NBER WORKING PAPER SERIES

\title{
ESTIMATING SECTORAL CYCLES \\ USING COINTEGRATION AND \\ COMMON FEATURES
}

Rober F. Engle

Joāo Victor Issler

Working Paper No. 4529

\section{NATIONAL BUREAU OF ECONOMIC RESEARCH 1050 Massachusetts Avenue \\ Cambridge, MA 02138 \\ November, 1993}

We gratefully acknowledge helpful comments from John Conlisk, Wouter Den Haan, Jesus Gonzalo, Clive W.J. Granger, Takeo Hoshi, Sharon Kozicki, Pedro Valls Pereira, Valerie Ramey and Farshid Vahid, who are not responsible for any remaining errors in this paper. João Victor Issler thanks CNPq-Brazil for financial support. This paper is part of NBER's research program in Economic Fluctuations. Any positions or opinions expressed are those of the authors and not those of the National Bureau of Economic Research. 
NBER Working Paper \#4529

November 1993

\title{
ESTIMATING SECTORAL CYCLES \\ USING COINTEGRATION AND \\ COMMON FEATURES
}

\begin{abstract}
$\underline{\text { ABSTRACT }}$
This paper investigates the degree of shor run and long run comovement in U.S. sectoral output data by estimating sectoral trends and cycles. A theoretical model based on Long and Plosser (1983) is used to derive a reduced form for sectoral output from first principles. Cointegration and common features (cycles) tests are performed and sectoral output data seem to share a relatively high number of common trends and a relatively low number of common cycles. A special trend-cycle decomposition of the data set is nerformed and the results indicate a very similar cyclical behavior across sectors and a very different behavior for trends. In a variance decomposition exercise, for prominent sectors such as Manufacturing and Wholesale/Retail Trade, the cyclical innovation is more important than the trend innovation.

Robert F. Engle

Departme:: of Economics

University of California, San Diego

La Jolla, CA 92093-0508

and NBER

João Victor Issler

Department of Econciso

University of California, San Diego

La Jolla, CA 92093-0508
\end{abstract}




\section{Introduction}

The goal of this paper is to examine the degree of short and long run comovement in U.S. output series. The methodology used is described in Vahid and Engle(1992), which extends the discussion of common features in Engle and Kozicki(1990). The use of this multivariate technique allows dealing with series which simultaneously contain common tends and common cycles. We focus our attention on sectoral per-capita GNP series to be able to cover a wide range of economic activity while keeping tractable the dimension of our data set. A special trend-cycle decomposition of the data is performed, which allows implementing a variance decomposition of sectoral output innovations.

The first thorough study of business cycles was done by Bums and Mitchell(1946). They decomposed several economic series into two distinct parts: a permanent component (or trend) and a cyclical component. Business cycles, as reported in their book, have two major stylized facts: persistence and comovement. The first can be described in an econometric sense as positive autocorrelation. For example, periods of unusually high output tend to cluster together. The second can be described as a tendency for different macro series to display similar short run fluctuations. These stylized facts have survived the test of time: they are stressed in Lucas(1977) and in the Real Business Cycles (RBC) literature started by Kydland and Prescott(1982) and Long and Plosser(1983).

The Keynesian paradigm incorporated Bums and Mitchell's idea of business cycles and went further in identifying fiscal and monetary policies as the driving forces of cyclical fluctuations. Then, econometric methods of estimating cycles consisted in detrending macro series by extracting their deterministic trend components, usually a linear time trend. In such trend stationary world cyclical components are very important, since they account for all wiggles of economic series. 
As a result of the work of Nelson and Plosser(1982), macroeconomists started to believe that most economic series should be treated as unit root processes [I(1)]. As a consequence, cointegration became an important approach in evaluating linear equilibrium conditions (see Granger(1983 and 1986)). A New method of detrending univariate I(1) macro series was developed by Beveridge and Nelson(1981) and extended to deal with multivariate I(1) data by Stock and Watson(1988). For I(1) series, the trend component is very important, since it cointegrates with the original series to generate the $I(0)$ cyclical component.

All the macroeconometric developments occurred in the 1980's reshaped the way macro theorists modelled business cycles. In the RBC literature, integrated productivity shocks are the source of integrated sectoral outputs, e.g., Long and Plosser(1983), and the source of cointegrated consumption, investment and output series, e.g, King, Plosser and Rebelo(1988b).

There has been a recent change in gears in macroeconomics since Bums and Mitchell published their influential book. Before, theorists believed that cyclical components were the source of economic fluctuations, whereas currently, the RBC literature emphasizes the importance of trend components. Most RBC models consider I(1) productivity shocks as the only source of randomness. As a result, not only do trend innovations have a permanent effect on the level of macro series, but they trigger cyclical fluctuations as well ${ }^{1}$. The empirical evidence for RBC models is not different: King, Plosser, Stock and Watson's(1991) variance decomposition results only grant a limited role for cyclical innovations. In a sense, we observe today a business cycle theory where cycles themselves are of secondary importance.

From the introduction of Burns and Mitchell(1946) (see pp 3-22), several interesting questions remain open about business cycles. Among them: (i) Is general business activity

1 Again, Long and Plosser(1983) and King, Plosser and Rebelo(1988b) are examples. 
generated by one common cycle? (ii) Are there differences in amplitude or counter-cyclicallity for different output series? In addition to these imporant old questions, there are some new ones raised by the RBC literature. They are: (i) What is the importance of trend and cyclical innovations for output fluctuations? (ii) What is the correlation between trend and cyclical components, and between trend and cyclical innovations?

We try to answer these questions using U.S. per-capita sectoral GNP. The stylized facts for these data are similar to that of most macro series:

(i) After testing, Durlauf(1989) concluded that they are I(1), which is in line with the general findings in Nelson and Ploser(1982).

(ii) Durlauf also reported some evidence of bivariate cointegration among different sectors. This is not surprising given the degree of interdependence among them.

(iii) Their Fluctuations display persistence and comovement as characterized by Lucas(1977) (see section 2) and explicitly modelled by Long and Plosser(1983).

Given the stylized facts about sectoral outputs, it is desirable to use an econometric technique which accommodates them in ying to answer the questions pose. Engle and Granger(1987) provide a unified theoretical framework to deal with multivariate data sets where variables contain a reduced number of stochastic trends. The introduction by Engle and Kozicki(1990) of the concept of common features and the refinements in Vahid and Engle(1992) provide a unified way to discuss data sets in which variables display both long run comovement (common stochastic trends) and short run comovement (common serial correlation). The contribution of our paper is to discuss important business cycles issues using an appropriate newly developed econometric technique. Also, the fact that we work with disaggregated data provides insights on idiosyncratic elements of economic sectors. 
Even though the econometric techniques are at hand, it is desirable to use a theoretical model which is able to explain the phenomena being considered. A macroeconomic model based on Long and Plosser(1983) is developed to explain the important stylized facts of sectoral output data outlined above. This model is used as a basic structure for econometric estimation. It also connects macroeconomic modelling and econometric estimation in the spirit of King, Plosser, Stock and Watson(1991).

Section 2 reviews the concept of common features applied to business cycles and discusses testing cointegrated series for common cycles. It also discusses ways of identifying trend and cycle of integrated series which display short and long run comovement. Section 3 presents a macroeconomic model able to generate a multivariate system for sectoral outputs displaying these features. It is an extension of Long and Plosser's(1983) model, augmented to accommodate cointegrated sectoral output series. Section 4 presents system estimates and the results of cointegration and common features tests. It also presents the results of a trend-cycle decomposition for sectoral output. Section 5 concludes.

\section{Common Features Tests}

According to Engle and Kozicki(1990) two stationary and ergodic series have a common feature if each of them individually exhibits the feature and there exists a linear combination of them which doesn't. To illustrate this concept, consider the following system²:

$$
\left(\begin{array}{l}
y_{1 t} \\
y_{21}
\end{array}\right)=\left(\begin{array}{l}
1 \\
\lambda
\end{array}\right) \omega_{t}+\left(\begin{array}{l}
\varepsilon_{1 t} \\
\varepsilon_{2 t}
\end{array}\right)
$$

2 Notice that due to stationarity and ergodicity assumptions on $y_{16}$ and $y_{2 n}$, if we are considering $I(1)$ variables, these have to be differenced to have a representation such as (2.1). 
Where the disturbance $\left(\varepsilon_{1 r}, \varepsilon_{2 t}\right)^{\prime}$ is white noise and possibly $\operatorname{COV}\left(\varepsilon_{1 t}, \varepsilon_{2}\right) \neq 0$. The latent variable $\omega$, is the feature. Given that we are interested in modelling business cycles, we assume that $\omega_{r}$ is a serially correlated latent variable which captures the common persistence in the series $y_{1 t}$ and $y_{2 t}$. Clearly, $y_{1 t}$ and $y_{2 t}$ are serially correlated, but $y_{2 t}-\lambda y_{1 t}=\varepsilon_{2 t}-\lambda \varepsilon_{1 t}$ is not. This suggests that the serial correlation is common. The vector $(-\lambda, 1)^{\prime}$ is called the cofeature vector.

Vahid and Engle(1992) discuss the same issue in a multivariate framework, where series are allowed to be integrated processes with common stochastic trends. They stant their aralysis assuming that the reduced form for the variables of interest can be represented by a Vector Autoregression (VAR) of order $\mathbf{k}$. In doing so, they avoid dealing explicitly with latent variables such as $\omega_{t}$ in (2.1). The reduced form is considered to be:

$A(L) y_{t}=\varepsilon_{t}$

Where $A(L)=\sum_{i=0}^{k} A_{i} L^{i} \quad ; \quad A(0)=I_{N} \quad ; \quad \underset{N \times 1}{y_{1}} ; \underset{N \times 1}{\varepsilon_{\mathrm{f}}} ; \underset{N \times N}{A_{i}}$

The $y_{i}$ 's represent a stack of sectoral outputs and the $\varepsilon_{t}$ 's are white noise. If the y's are

cointegrated, by the Granger Representation Theorem, e.g. Engle and Granger(1987), there is an Error Correction (EC) representation of this system as follows:

$\Delta y_{t}=-A(1) y_{t-1}+\sum_{i=1}^{k-1} A_{i} \Delta y_{r-i}+\varepsilon_{t}$

Where $A_{i}^{\cdot}=-\left(A_{i+1}+\cdots+A_{k}\right) \quad \forall i=1,2, \ldots, k-1$

Moreover, if we stack all $\mathbf{r}$ linearly independent cointegrating vectors in a $\mathbf{r} \times \mathbf{N}$ matrix $\alpha^{\prime}$, then, $\gamma \alpha^{\prime}=A(1)$, where $\gamma$ is a full column rank $N \times \mathbf{r}$ matrix. From $\gamma \alpha^{\prime}=A(1)$, any element of the cointegrating space, say, $\alpha_{1}{ }^{\prime}$, is an element of the column space of $A(1)^{\prime}$. Consider now a 
cofeature vector, say, $\tilde{\alpha}_{1}^{\prime}$. Since a cofeature vector has the property of cancelling the serial correlation of the $\Delta y_{t}$ 's, it must lie simultaneously on the left null spaces of $A(1)$ and $\sum_{i=1}^{k-1} A_{i}$. Thus, pre-multiplying (2.3) by $\bar{\alpha}_{1}^{\prime}$ yields:

$\bar{\alpha}_{1}^{\prime} \Delta y_{t}=\bar{\alpha}_{1}^{\prime} \varepsilon_{t}$

Therefore, $\vec{\alpha}_{1}{ }^{\prime} \Delta y_{t}$ is white noise. There are two important implications from this result: first, if we integrate $\tilde{\alpha}_{1}^{\prime} \Delta y_{s}$, we find that $\tilde{\alpha}_{1}^{\prime} y_{t}$ is a random walk, thus with serially uncorrelated innovations. Therefore, the vector that removes the serial correlation of the $\Delta y_{1}$ 's also removes the cyclical component of the $y_{t}$ 's. Second, since $\tilde{\alpha}_{1}$ is an element of the left null space of $A(1)$ it must be orthogonal to the cointegrating space, i.e., the space spanned by all linearly independent cointegrating vectors. The last result is a very important theoretical link between the cointegrating space and the cofeature space. It follows from it that if there are $r$ linearly independent cointegrating vectors, there can be at most $\mathbf{N}-\mathbf{r}$ linearly independent cofeature vectors. Notice that there is no guarantee that this upper bound will be achieved. When it is, however, a special trend-cycle decomposition of the $y_{t}$ 's is possible as discussed below.

We now turn to estimation of the cointegrating space and the cofeature space. From the discussion above, we have to consider testing methods that allow estimating the cointegrating rank and the cofeature rank. The testing procedure we propose has two steps: first we estimate the cointegrating rank and conditioned on the results we estimate the cofeature rank. For both estimations we use reduced rank regression methods: for cointegration, we use Johansen's(1988) technique and for common features we use canonical correlation analysis.

Let's start the discussion of the testing procedure by assuming that the data can be approximately described by a finite VAR of order $k$, with Gaussian errors, and augmented by a constant and a linear trend terms as follows: 
$y_{t}=\sum_{i=1}^{k} A_{i} y_{t-i}+\mu_{0}+\mu_{1} \cdot t+\varepsilon_{t}$

Where $y_{t}$ is a $\mathbf{N}$-column vector of random variables and $\varepsilon_{t} \sim \operatorname{IIN}(0, \Omega)$. The EC representation of (2.5) is:

$\Delta y_{1}=\gamma \alpha^{\prime} y_{t-1}+\sum_{i=1}^{k-1} A_{i}^{*} \Delta y_{t-i}+\mu_{0}+\mu_{1} \cdot t+\varepsilon_{t}$

Where $A_{i}^{*}=-\left(A_{i+1}+\ldots+A_{k}\right) \quad \forall i$ and $A(1)=\gamma \alpha^{\prime}$, where $\gamma$ and $\alpha$ are $\mathrm{N} \times \mathrm{r}$ matrices. The hypothesis of cointegration is defined as $H_{r}: \quad A(1)=\gamma \alpha^{\prime}$, i.e., that the rank of $\mathrm{A}(1)$ is less or equal to $r$, where $r<N$.

Johansen(1991a) modified the Granger Representation Theorem (see pp 1558-1561) to establish the representation of $\Delta y_{1}$ in (2.6) when $\mu_{1}=0$. His result can be easily extended for the case where $\mu_{1} \neq 0$ to prove that, apart linear trend, $\Delta y_{\text {, }}$ has an invertible moving average representation as follows:

$\Delta y_{i}=C(L)\left(\varepsilon_{i}+\mu_{0}+\mu_{1} \cdot l\right)$

That $y_{t}$ is non-stationary with a quadratic trend and that $\alpha^{\prime} y_{1}$ is trend stationary as follows:

$$
\begin{aligned}
y_{t}= & C(1) \sum_{i=1}^{1} \varepsilon_{i}+C^{*}(L) \varepsilon_{t}+C^{\prime}(1) \mu_{0}-\sum_{i=1}^{\infty} i C_{i}^{*} \mu_{1}- \\
& -\left[C(1)-C^{*}(1)\right] \mu_{1} \cdot t+\frac{1}{2} C(1) \mu_{1} \cdot t^{2} \\
\alpha^{\prime} y_{1}= & \alpha^{\prime} C^{*}(L) \varepsilon_{i}+\alpha^{\prime} C^{*}(1) \mu_{0}-\alpha^{\prime} \sum_{i=1}^{-} i C_{i}^{*} \mu_{1}+\alpha^{\prime} C^{*}(1) \mu_{1} \cdot t
\end{aligned}
$$


Where $C(L)$ is decomposed as $C(L)=C(1)+C^{*}(L)(1-L)$ and $C(1)=\alpha_{p}\left[\gamma_{p}^{\prime}\left(I-\sum_{i=1}^{k-1} A_{i}^{*}\right) \alpha_{p}\right]^{-1} \gamma_{p}{ }^{\prime}$, where $\alpha_{p}$ and $\gamma_{p}$ are the orthogonal complements of $\alpha$ and $\gamma$ respectively ${ }^{3}$.

The peculiar feature of (2.6) is that Error Correction terms are trend stationary. Therefore, in testing for cointegration, this has to be taken into account. The reason we discuss this more general VAR representation here is because our data seems to conform well to a process like (2.5) above. Johansen(1991b) discusses testing for cointegration under these conditions. The procedure involves a slight modification of the one discussed in Johansen(1988): using the EC model, first run a regression of $\Delta y_{\text {, }}$ on lagged $\Delta y$ 's, a constant and a time trend. Denote the residuals from this regression as $R_{0 t}$. Second, run a regression of $y_{t-1}$ on the same variables, denoting the residuals as $R_{1 i}$. The rest of the testing procedure follows Johansen(1988). The asymptotic distribution of the likelihood ratio test $Q_{r}=-2 \ln Q\left(H_{r} \mid H_{N}\right)$ of $H_{r}$ in $H_{N}$, i.e., that the cointegrating rank is $\mathbf{r}$, changes vis-a-vis the one presented in Johansen(1988). This issue is discussed in Johansen(1991b).

Using the concentrated likelihood function, one can test the hypothesis that a given data set conforms to the VAR specification in (2.5) instead of its restricted version with $\mu_{1}=0$. According to Johansen(1991b), the likelihood ratio test for the null that $\mu_{1}=0$ is asymptotically distributed $\chi^{2}(N)$.

3 The proof is available upon request. 
Given the restrictions on the VAR found from the cointegrating tests, one can form an EC model with the number of EC terms equal to the cointegrating rank. This EC model will itself have cross equations restrictions if the variables have common serial correlation. As discussed above, the cross equation restrictions are a result of $\gamma \alpha^{\prime}$ and $\sum_{i=i}^{k-1} A_{i}^{*}$ having the same left null space, which imply that there are linear combinations of the $\Delta y_{1}$ 's which are white noise.

The method of finding the cofeature rank incorporates the restrictions of cointegration by using the EC model. We look for linear combinations of the $\Delta y_{1}$ 's which are white noise. Since all the serial correlation of the $\Delta y$,'s is captured by the conditioning variables on the RHS of (2.6), we should look for linear combinations of the $\Delta y_{i}$ 's which are uncorrelated with any linear combination of these conditioning variables. Notice that performing such orthogonality tests is exactly the object of canonical correlation analysis.

The idea behind canonical correlations is simple: suppose we have two sets of variables. The first is $\Delta y_{1}^{\prime} \equiv\left(\Delta y_{1}, \Delta y_{2 n}, \ldots, \Delta y_{N}\right)^{\prime}$, i.e., the variables in the LHS of (2.6), and the second is $z^{\prime}, \equiv\left(\Delta y_{i-1}^{\prime}, \ldots, \Delta y_{t-k+1}^{\prime},\left(\alpha^{\prime} y_{t-1}\right)^{\prime}, 1, t\right)^{\prime}$, i.e., the conditioning variables in the RHS of (2.6). Let $u_{i r} \equiv \tilde{\alpha}_{i}^{\prime} \Delta y_{i}$ and $v_{i f} \equiv \beta_{i}^{\prime} z_{r}, i=1,2, \ldots, N$, be specific linear combinations of the $\Delta y_{i}^{\prime}$ 's and the $z_{i}^{\prime} s$ respectively. The goal is to get a maximal correlation coefficient between $u_{i t}$ and $v_{i r}$, $i=1,2, \ldots, N$. The set of the $\mathbf{N}$ orthogonal choices of the $\bar{\alpha}_{i}$ 's and $\beta_{i}$ 's is such that they deliver such optima, which are called canonical correlations (for an introduction see Anderson(1984) pp 480-519).

From the discussion above, it is clear what canonical correlation analysis provides: each statistically zero canonical correlation represents a linear combination of the $\Delta y_{y}$ 's uncorrelated with all linear combination of the $z_{r}$ 's, since it is uncorrelated with the one which delivers maximal correlation between $u_{i r}$ and $v_{i i}$. The cofeature rank, $\mathbf{s}$, is the number of statistically zero 
canonical correlations, where $s \leq N-r$, and the number of common cycles is ${ }^{4} \mathrm{~N}-\mathrm{s}$. Clearly, the number of common cycles is the number of non-zero canonical correlations. The $\mathbf{N} \times \mathbf{s}$ full rank matrix $\bar{\alpha}$, which stacks all the $\bar{\alpha}_{i}$ 's associated with the zero canonical correlations, is a basis for the cofeature rank.

Vahid and Engle(1992) discuss a special case on the dimensions of the cointegrating and cofeature ranks, for it generates a unique trend-cycle decomposition of the data. Suppose the cointegrating rank - $r$, and the cofeature rank - $s$ add up to the number of variables in the data set, i.e., $\mathrm{N}=\mathrm{r}+\mathrm{s}$. The common trend representation of the system (2.5) is given by:

$$
\begin{aligned}
y_{t}=C(1) \sum_{i=1}^{\prime} \varepsilon_{i}+C^{*}(L) \varepsilon_{t}+C^{*}(1) \mu_{0}-\sum_{i=1}^{\infty} i C_{i}^{*} \mu_{1}- \\
-\left[C(1)-C^{*}(1)\right] \mu_{1} \cdot t+\frac{1}{2} C(1) \mu_{1} \cdot t^{2}
\end{aligned}
$$

Equation (2.10) is more than a common trend representation: there are common trends whenever the rank of $\mathrm{C}(1)$ is less than $\mathbf{N}$. What about common cycles? The cycles are generated by $C^{*}(L) \varepsilon_{r}$, therefore there are common cycles whenever $C^{*}(L)$ is reduced rank. When $\mathrm{N}=\mathrm{r}+\mathrm{s}$, we can explore the reduced ranks of both $C(1)$ and of $C^{*}(L)$ as follows: first collect all independent cointegrating vectors in a $\mathrm{N} \times \mathbf{r}$ matrix $\alpha$ and all independent cofeature vectors in a $\mathbf{N} \times \mathbf{s}$ matrix $\tilde{\alpha}$. We know that every element of the cointegrating space eliminates the stochastic trends and every element of the cofeature space eliminates the cycles. Thus:

4 The reasoning is identical to the one in the common trend literature, e.g. Stock and Watson(1988). 
$\alpha^{\prime} y_{t}=\alpha^{\prime} C^{*}(L) \varepsilon_{1}+\alpha^{\prime} C^{*}(1) \mu_{0}-\alpha^{\prime} \sum_{i=1}^{\infty} i C_{i}^{*} \mu_{1}+\alpha^{\prime} C^{*}(1) \mu_{1} \cdot t$

and

$\tilde{\alpha}^{\prime} y_{t}=\tilde{\alpha}^{\prime} C(1) \sum_{i=1}^{t} \varepsilon_{i}-\tilde{\alpha}^{\prime} \sum_{i=1} i C_{i} \mu_{1}-\bar{\alpha}^{\prime} C(1) \mu_{1} \cdot t+\frac{1}{2} \bar{\alpha}^{\prime} C(1) \mu_{1} \cdot t^{2}$

Notice that (2.11) contains no stochastic trends, only trend-stationary cycles, and that (2.12) contains no cycles, only stochastic and deterministic trends. Suppose we now stack $\bar{\alpha}^{\prime}$ and $\alpha^{\prime}$ as follows:

$\left[\begin{array}{c}\overline{\alpha^{\prime}} \\ , \times N \\ \overline{\alpha^{\prime}} \\ x \times N\end{array}\right] y_{t}=\left[\begin{array}{c}\tilde{\alpha}^{\prime} C(1) \sum_{i=1}^{1} \varepsilon_{i}-\bar{\alpha}^{\prime} \sum_{i=1} i C_{i}^{\prime} \mu_{1}-\tilde{\alpha}^{\prime} C(1) \mu_{1} \cdot t+\frac{1}{2} \bar{\alpha}^{\prime} C(1) \mu_{1} \cdot t^{2} \\ \alpha^{\prime} C^{\prime}(L) \varepsilon_{t}+\alpha^{\prime} C^{\prime}(1) \mu_{0}-\alpha^{\prime} \sum_{i=1} i C_{i}^{\prime} \mu_{1}+\alpha^{\prime} C^{\prime}(1) \mu_{1} \cdot t\end{array}\right]$

Define now the matrix $A$ to be:

$A=\left[\begin{array}{c}\tilde{\alpha}^{\prime} \\ s \times N \\ -\overline{\alpha^{\prime}} \\ r \times N\end{array}\right]$,

Since the cointegrating and cofeature spaces are orthogonal and $r+s=N$, the matrix $A$ is full rank.

Consider the following partition of $\mathbf{A}^{-1}$, conformable to $\mathbf{A}$ :

$A^{-1}=\left[\begin{array}{ccc}\bar{a} & \mid & a \\ N \times s & & N \times r\end{array}\right]$.

Pre-multiply (2.13) by $\mathbf{A}^{-1}$ to obtain: 


$$
\begin{aligned}
y_{t}= & \tilde{a} \tilde{\alpha}^{\prime} C(1) \sum_{i=1}^{1} \varepsilon_{i}-\tilde{a} \tilde{\alpha}_{i=1}^{\prime} \sum_{i=1} i C_{i}^{*} \mu_{1}-\bar{a} \bar{\alpha}^{\prime} C(1) \mu_{1} \cdot t+\frac{1}{2} \tilde{a} \tilde{\alpha}^{\prime} C(1) \mu_{1} \cdot t^{2} \\
& +a \alpha^{\prime} C^{*}(L) \varepsilon_{i}+a \alpha^{\prime} C^{*}(1) \mu_{0}-a \alpha^{\prime} \sum_{i=1} i C_{i}^{*} \mu_{1}+a \alpha^{\prime} C^{*}(1) \mu_{1} \cdot t
\end{aligned}
$$

Equation (2.14) is a trend-cycle decomposition: the top line in its RHS only contains stochastic and deterministic trends, while the bottom line only contains trend-stationary cyclical elements ${ }^{5}$. Since it is usual practice in the literature to have a cyclical component free of deterministic elements, we opt to assign $a \alpha^{\prime} C^{*}(1) \mu_{0}-a \alpha^{\prime} \sum_{i=1}^{\infty} i C_{i}^{*} \mu_{1}+a \alpha^{\prime} C^{*}(1) \mu_{1} \cdot t$ to the trend part. If we do it and use equations (2.11) and (2.12) into (2.14), we can decompose $y_{t}$ into two parts: a permanent component $-y_{t}^{p}$, which has the stochastic trend and all deterministic components of $y_{s}$, and a cyclical component $-y_{t}^{e}$, which is a pure non-deterministic cycle. Notice that we can carry on this exercise without resorting to any knowledge of $C(L)^{6}$ :

$y_{1}=y_{i}^{p}+y_{t}^{e}$

$$
\text { Where } \begin{aligned}
y_{t}^{c} & =a \alpha^{\prime} y_{t}-a \alpha^{\prime} C^{*}(1) \mu_{0}+a \alpha^{\prime} \sum_{i=1}^{\infty} i C_{i}^{*} \mu_{1}-a \alpha^{\prime} C^{*}(1) \mu_{1} \cdot t \\
y_{t}^{p} & =a \alpha^{\prime} y_{s}+a \alpha^{\prime} C^{\prime}(1) \mu_{0}-a \alpha^{\prime} \sum_{i=1}^{\infty} i C_{i}^{*} \mu_{1}+a \alpha^{\prime} C^{*}(1) \mu_{1} \cdot t
\end{aligned}
$$

5 It is easier to conceive the trend-cycle decomposition when $\mu_{0}=\mu_{1}=0$, since in that case:

$y_{i}=\tilde{a} \tilde{\alpha}^{\prime} \sum_{i=1}^{l} \varepsilon_{i}+a \alpha^{\prime} C^{\cdot}(L) \varepsilon_{i}$.

The first term contains only common stochastic trends and the second contains only common cycles.

6 Although is not apparent from equations (2.16) and (2.17), the deterministic part of $y_{t}^{c}$ need not be estimated using $C(L)$. One can simply project the trend-stationary cycle on a constant and a linear trend and use the knowledge of $a \alpha^{\prime}$ to calculate

$a \alpha^{\prime} C^{*}(1) \mu_{0}-a \alpha^{\prime} \sum_{i=1}^{\infty} i C_{i}^{*} \mu_{1}+a \alpha^{\prime} C^{*}(1) \mu_{1} \cdot t$. 
There are two important facts about the trend-cycle decomposition in (2.15): first, it is unique, i.e., performing linear transformations in the cointegrating space or cofeature space in isolation will not change the estimated trend and cycles. Second, $y_{r}^{c}$ is just a linear combination of the detrended Error Correction terms. Here, the Error Correction terms can be viewed as cycle generators, which emphasizes their importance in macroeconometrics.

There is a clear advantage in using a decomposition such as this one: we need not impose any improbable conditions to be able to identify trend and cyclical components. The same is not true about other such decompositions, e.g. Blanchard and Quah(1989) and King, Plosser, Stock and Watson(1991). In these, an orthogonality condition between innovations to the permanent component and purely transitory innovations is needed for identification. The reason we need not impose such restrictions here is because we exploit the fact that both $C(1)$ and $C^{\circ}(L)$ are reduced rank and that $\mathbf{N}=\mathbf{r}+\mathbf{S}$.

\section{A Real Business Cycles Model for Sectoral Output}

One of the few models attempting to derive persistence and comovement of sectoral output from optimizing behavior is Long and Plosser(1983). This RBC model explains these features based solely on idiosyncratic technology shocks. As noted by Mankiw(1989), RBC models are an extreme version of dynamic Walrasian Equilibrium models in which money plays no active role. Trying to explain persistence and comovement using such extreme models can lead to incomplete or misleading explanations of how macroeconomic fluctuations come about. Nevertheless, RBC models are still useful, in what they are internally consistent theoretical models, with rational optimizing agents, which deliver some intuition of how macroeconomic variables interact. 
Long and Plosser set up a dynamic programming problem solved in a Robinson Crusoe type of economy, where an infinitely lived agent maximizes discounted expected utility subject to technology constraints. The optimization problem is the following:

$$
\begin{array}{lrl}
\operatorname{Max} & E_{t} \sum_{j=0}\left[\theta_{0} \ln Z_{t+j}+\sum_{i=1}^{N} \theta_{i} C_{i t+j}\right] & \text { s.t. } \\
Y_{i t+1}=\lambda_{i t+1} L_{i t}^{b_{i}} \prod_{j=1}^{N} X_{i j t}^{a_{i j}} ; & \forall t ; j=1,2, \ldots, N \\
Z_{t}+\sum_{i=1}^{N} L_{i t}=H ; & \forall t ; j=1,2, \ldots, N \\
C_{j t}+\sum_{i=1}^{N} X_{i j t}=Y_{j t} ; & \forall t \\
\theta_{0}>0 ; \quad \theta_{i} \geq 0, b_{i}+\sum_{j=1}^{N} a_{i j}=1 ; & i=1,2, \ldots, N
\end{array}
$$

Where $Y_{i t}$ is a the produced quantity of commodity $\mathrm{i}, \mathrm{i}=1,2, \ldots, \mathrm{N}$, and $Y_{t}$ is a vector containing all individual production. Each good can be used either for consumption $\left(C_{i t}\right)$ or as input in producing other goods $\left(X_{i j t}\right)$, where $X_{i j t}$ is the quantity of good $\mathbf{j}$ used in producing good $\mathbf{i}$. Since for production to take place inputs have to be readily available, it is assumed that period t's production uses inputs produced in period t-1. Production of commodity i requires also some use of labor, $L_{i r}$. There are $\mathrm{N}$ sectoral technology shocks $\lambda_{i s}$, stacked in a column vector $\lambda_{r}$, where $\left\{\lambda_{i}\right\}$ is assumed to be a jointly time homogeneous Markov process. The particular choices of utility and production functions used reflect the goal of obtaining closed form solutions for the choice variables ${ }^{7}$.

The competitive equilibrium solution is found by applying the second "Welfare Theorem." The optimal solutions for consumption, labor and input quantities are given by:

7 Production functions are Cobb-Douglas with constant returns in all sectors. 


$$
\begin{array}{rlr}
C_{i t}^{*}=\left(\frac{\theta_{i}}{\gamma_{i}}\right) Y_{i t} ; & i=1,2, \ldots, N \\
X_{i j t}^{*}=\left(\frac{\beta \gamma_{i} a_{i j}}{\gamma_{j}}\right) Y_{j t} ; & i, j=1,2, \ldots, N \\
L_{i t}^{*}=\beta \gamma_{i} b_{i}\left(\theta_{0}+\beta \sum_{j=1}^{N} \gamma_{j} b_{j}\right)^{-1} H ; & i=1,2, \ldots, N
\end{array}
$$

Where the $\gamma_{j}$ 's are elements of the vector $\gamma^{\prime}=\theta(I-\beta A)^{-1}$, where $\theta=\left(\theta_{1}, \theta_{2}, \ldots, \theta_{N}\right)$ and $A=\left(a_{i j}\right)$.

There is an important property of the optimal solution for $X_{i j t}^{*}$ above. If output of good $j$ is unexpectedly high at time $t$, inputs of commodity $\mathbf{j}$ will be unexpectedly high in period $\mathrm{t}$ as well. If commodity $j$ has several uses as an input, the positive shock will migrate across sectors. Moreover, there is a tendency for this shock to propagate forward in time. Since most sectoral outputs are unexpectedly high in period $t$, endowments of most commodities will be high in period $t+1$, which will trigger higher than usual outputs in $\mathbf{t}+1$. Therefore, this theoretical model is able to explain sectoral output persistence and comovement, which is a stylized fact of business cycles. However, it fails completely to address issues such as frictions due to sectoral shifts, for which Lilien(1982) provided some evidence. Our empirical evidence will discuss these two seemingly competing models.

Using the optimal input decision rules for the Cobb-Douglas production function, Long and Plosser are able to derive the dynamic behavior of (log) sectoral output. The reduced form of the system is summarized by the following expression:

$\log Y_{t}=K+A \log Y_{t-1}+\log \lambda_{t}$

Where $\mathrm{K}$ is a function of the preference parameters $\beta$ and $\theta_{i} \quad ; \quad i=0,1, \ldots, N$. 
The matrix A plays an important role in the dynamics of sectoral outputs. Recall that the $a_{i j}$ 's are input elasticities in production. Thus, $\mathbf{A}$ is a non-negative matrix. If labor is used in positive amounts, from the constant returns to scale assumption on the production functions, $\sum_{j=1}^{N} a_{i j}<1$ holds. Thus, $\mathbf{A}$ is stable, i.e., all its eigenvalues lie between zero and one in absolute value $^{8}$. To achieve sectoral outputs that are $I(1)$ processes, Long and Plosser required $\left\{\log \lambda_{4}\right\}$ to be $I(1)$ in the following way:

$\log \lambda_{i t}=\log \lambda_{i t-1}+\varepsilon_{i t} \quad ; \quad i=1,2, \ldots, N$

Where $\varepsilon_{t} \equiv\left(\begin{array}{c}\varepsilon_{1 ;} \\ \ldots \\ \varepsilon_{N_{t}}\end{array}\right) ; \quad E\left(\varepsilon_{t}\right)=0 ; \quad E\left(\varepsilon_{t} \varepsilon_{s}\right)=\left\{\begin{array}{lc}I & \text { for } \mathrm{t}=\mathrm{s} \\ 0 & \text { for } \mathrm{t} \neq \mathrm{s}\end{array}\right\}$

i.e., $(\log )$ productivity shocks are assumed to be uncorrelated random walks. Of course, this assumption implies that all $\log \left(\mathrm{Y}_{\mathrm{i}}\right)$ 's will have a unit root as well, however, it has some other important implications attached to it. The first one is that (3.4) will not be the VAR representation of the $\log (Y)$ 's, since the $\log \lambda$ 's are not I(O). The VAR representation of the system can be found by taking first differences of (3.4) as follows:

$\Delta \log Y_{t}=A \Delta \log Y_{t-1}+\varepsilon_{t}$

Which can be rewritten as:

$A(L) \log Y_{s}=K^{\prime}+\varepsilon_{\mathrm{r}}$

Where $A(L) \equiv\left(I-(A+I) L+A L^{2}\right)$

8 This fact is proven in Proposition 3.1 below. 
i.e., the system is a VAR of order 2 . This VAR has the property that $A(1)=0$, therefore, there is no cointegration among the $\log (Y)$ 's. However, evidence in Durlauf(1989) contradicts it and suggests expansion of this dynamic specification.

It is now useful to ask under which conditions will non-cointegrated sectoral outputs as in (3.7) deliver common serial correlation. The answer is straightforward. We are asking if there are some $\mathbf{N} \times 1$ vectors $\bar{\alpha}_{i}$ such that $\bar{\alpha}_{i}^{\prime} A=0$. Thus, common serial correlation requires the matrix $A$ to be reduced rank, i.e., that there exists some sort of (log) linear dependence among production processes. Moreover, all sectors will only share a common cycle if $\mathrm{A}(1)$ has rank one, i.e., the input mix for all enterprises is the same.

Summarizing the econometric implications of the theoretical model in Long and Plosser(1983): (i) in general, both $\log Y_{i s}$ 's and $\Delta \log Y_{i t}$ 's will display serial correlation; (ii) because the matrix $\mathbf{A}$ is stable, in order to get $\log (\mathbf{Y})$ 's which are I(1), Long and Plosser imposed the $\log \lambda_{1}$ 's to be uncorrelated random walks. This implies that the $\log (\mathrm{Y})$ 's are not cointegrated; (iii) as long as $\mathbf{A}$ is reduced rank, the serial correlation of the $\Delta \log Y_{i r}$ 's will be common. As discussed before, this implies that the $\log Y_{\text {it }}$ 's will have common cycles.

We propose modifying Long and Plosser's model in order to account for cointegration while preserving its persistence and comovement implications. A natural extension of the model is to allow for cointegration of the $\log (Y)$ 's by requiring the $\log \lambda_{i i}$ 's to be cointegrated. For example. consider:

$\log \lambda_{t}=\Phi \log \lambda_{1-1}+\eta_{t}$

Where $\left\{\eta_{t}\right\}$ is white noise. Assume further that each element of $\log \lambda_{t}$ is $I(1)$ and that $(I-\Phi)$ is reduced rank. In this case the $\log \lambda_{i}$ 's will share common stochastic trends. Combining (3.8) and (3.4) we get the following VAR representation for the $\log (Y)$ 's: 
$A(L) \log Y_{1}=(I-\Phi) K+\eta_{1}$

Where $\quad A(L) \equiv\left[I-(A+\Phi) L+\Phi A L^{2}\right]=[(I-\Phi L)(I-A L)]$

i.e., a VAR of order 2. Its EC representation is:

$\Delta \log Y_{t}=(I-\Phi) K-(I-\Phi)(I-A) \log Y_{t-1}+\Phi A \Delta \log Y_{t-1}+\eta_{t}$

We now state a very important result of the modified model (3.10):

Proposition 3.1: Given the model in Long and Plosser (1983), and assuming that $\left\{\log \lambda_{r}\right\}$ follows (3.8), if labor is used in all production processes, then, there is cointegration among sectoral outputs if and only if there is cointegration among productivity shocks. Moreover, under cointegration, the two cointegrating ranks coincide.

Proof: See appendix.

Proposition 3.1 delivers an intuitive result, since the $\log (Y)$ 's are integrated as a consequence of the $\log \lambda$ 's being integrated. The interesting feature of this result is that it rules out production processes as a source of cointegration for the $\log (Y)$ 's, since $(I-A)$ is necessarily full rank. Therefore, if productivity shocks are not cointegrated, there cannot be cointegration among sectoral outputs even if production processes are (log) linearly dependent. Because we assumed the $\log \lambda$ 's to be cointegrated, it follows that there is cointegration among the $\log (\mathrm{Y})$ ' $\mathrm{s}$.

Any cointegrating vector lies in the column space of $[(I-\Phi)(I-A)]^{\prime}$. What about common serial correlation? Decompose $\mathrm{A}(\mathrm{L})$ as follows: $A(L)=A(1) L+A^{*}(L)(1-L)$. Therefore, $A^{\circ}(L)=(I-\Phi A L)$. Common cycles among the $\log (Y)$ 's requires the intersection of the left null space of $(\Phi A)$ with that of $[(I-\Phi)(I-A)]$ to be non-empty, a feasible condition which emphasizes the relations between the technology process and the production function. 
In summary, the modification proposed in (3.8) provides an EC model (3.10) where it is possibie to have simultaneously: $\log (Y)$ 's which are I(1), cointegrated, and that share common cycles. It also provides a starting point for estimating a RBC system of sectoral outputs.

It is helpful to examine the macroeconomic implications of the modified model. The crucial point of our extension is to allow for cointegration among (log) productivity shocks, instead of requiring them to follow (3.5). Notice that since $A(1)=(I-A)(I-\Phi)$, and $(I-A)$ is full rank, the only way of generating cointegrated (log) sectoral outputs is to require (log) productivity shocks to be cointegrated, i.e, $(I-\Phi)$ to be reduced rank'. Cointegrated productivity shocks allow technological innovations in one sector to contribute to technological innovations in others. This seems to be a reasonable assumption, since, for example, the mass production of computers generated technological improvements in sectors other than Manufacturing.

\section{Empirical Evidence}

The multivariate procedures described in section 2 were applied to sectoral per-capita real GNP. Per-capita data is used since the theoretical model discussed in the previous section is that of a representative agent. Data consist of yearly $(\log )$ sectoral real GNP divided by total population, and is available from 1947 to $1989^{10}$. Sectors are a sub-division of private GNP as follows: Agriculture, Forestry \& Fisheries - A, Construction - Con, Mining - Min, Wholesale and Retail Trade - W, Manufacturing - M, Transporation and Public Utilities - T, Finance, Insurance \& Real Estate - $\mathbf{F}$ and Services $-\mathbf{S}^{11}$. A plot of the these data is presented in Figure 1 in

9 This fact is an obvious empirical test for Long and Plosser's RBC model, since the $\log (Y)$ 's are cointegrated. To follow up on this issue, however, one has to estimate productivity shocks, and this is no easy task (see the discussion on King, Plosser, Stock and Watson(1991)).

10 All data were extracted from Citibase. Sectoral private GNP is calculated at constant 1982 prices.

11 This is the only sectoral breakdown used in this paper. Sectors names are sometimes written in short to save space. 
the appendix. Most series show the familiar upward trend of macroeconomic variables, however it seems that they are trending at different rates. Figure 2 shows the shares of Private GNP of individual level series. This Figure reveals some important intersectoral dynamics: sectors like Wholesale/Retail Trade, Finance and Services had increased their share in Private GNP, while sectors like Agriculture, Mining and Construction had their shares reduced. On the other hand, for Manufacturing and Transportation there is neither a strong tendency to increase their share nor to decrease it, even though a slight hysteresis is observed for Manufacturing. The overall picture that emerges is that of a group of trending sectors with some evidence of sectoral shifts.

Durlauf(1989) tested the order of integration of sectoral per-capita GNP and concluded that these data are well approximated by an I(1) process ${ }^{12}$. Even though there is controversy about the power of unit root tests in distinguishing between different "Generic Unit Root ${ }^{13 . "}$ (GNR) processes, there is little doubt these tests are able to distinguish GNR from non-GNR processes. The I(1) specification is used here since there is a well developed methodology for dealing with it. If sectoral outputs contain stochastic trends, the next interesting question is to infer whether or not some of these are common across sectors. In testing sectors for cointegration, Durlauf finds some evidence of bivariate cointegration, although not widespread. Since the cointegrating rank must be estmated in our methodology, Johansen's(1988) technique is applied here. The results are reported in Table 1. We conclude that there exist two cointegrating vectors at the usual significance levels. A plot of these two cointegrating vectors

12 Since Durlauf tested several series identical to the ones used here, we will not conduct integration tests.

13 This terminology groups trending processes which all have near-unit roots and that are indistinguishable in the statistical sense for the limited amount of data macroeconomists possess. 
suggests that they may be stationary around a deterministic trend. Indeed, running them on a deterministic trend and a constant yields significant coefficients for both. As discussed in section 2, we may be dealing with a VAR which contains a linear trend, e.g. equation (2.5).

The next step was to test whether the VAR representation contains a deterministic linear trend. We used the Likelihood Ratio (LR) test obtained from the concentrated likelihood function, as suggested in Johansen(1991b). The LR statistic ${ }^{14}$ for this test is 48.35 , which rejects the null that the VAR representation (and the EC representation) does not contain a linear trend. The next step was to re-estimate the cointegrating vectors using the EC model in (2.6). The estimates of the two cointegrating vectors using the modified VAR representation are trend stationary, as expected. In order to extract their deterministic components we run them on a constant and a linear trend. The detrended cointegrating vectors are plotted in Figure 3. They both appear to be well behaved long run relationships.

Finding a small number of cointegrating vectors rules out the possibility that sectoral output data have one common stochastic trend. Indeed, since the cointegrating rank is two-dimensional, the eight sectors will share six independent common trends. This finding is consistent with the evidence presented in Durlauf(1989), which notes that one should not expect to find very different sectors sharing common stochastic trends if these arise from technology shocks. As he notes, a technological improvement in Agriculture does not imply improvement in Manufacturing, due to little spill-over effects among these sectors.

Table 2 presents the estimates of the EC model (2.6) conditioning on two lags of the endogenous variables. This corresponds to a VAR of order three, which, with yearly data. should be enough to capture the dynamics of the system. The EC model estimates are satisfactory,

14 This statistic is distributed as a $\chi^{2}(8)$ since we are imposing eight zero coefficient restrictions in the VAR. 
suggesting that the system can be well approximated by a VAR of order three with a linear trend. It is worth mentioning that all residuals passed normality $\operatorname{tests}^{15}$, a desirable feature since Johansen's(1988) test assumes Gaussian errors. Table 3 displays system significance levels for each regressor. Inclusion up to lag two of the endogenous yariables seem justified. Notice also the high explanatory power of the time trend in the system, corroborating the evidence of the LR test conducted previously.

In order to infer the cofeature rank, a canonical correlation analysis was conducted using the EC representation to capture the serial correlation in the system. Results are presented in Table 4. The F-test used in this table provides better small sample results than the usual $\chi^{2}$ approximation (see Rao(1973)). As noted before, the cofeature rank will be equal to the number of statistically zero canonical correlations. From Table 4 , at the $5 \%$ level, we conclude that the cofeature rank is six-dimensional. This implies that the eight sectors will share only two independent serially correlated cycles. Thus, we should observe a very similar cyclical behavior for different sectors; This feature is the basic thrust behind Burns and Mitchell's(1946) research, and is cited as a stylized fact in Lucas(1977), and is emphasized in Long and Plosser(1983 and 1987).

A particular attribute of our data set is that the cofeature and cointegrating rank add up to the number of variables. As discussed before, it allows a special trend-cycle decomposition of the data which exploits the reduced rank of the cofeature and cointegrating spaces. Figures 4 through 11 graph each individual sectoral output and its respective trend, estimated by the method described in section 2 . There are two striking characteristics of this set of results: first, trends display a very distinct behavior across sectors. This is not surprising since the eight sectors share six independent trends. Second, in most cases, the trend is more volatile than the

15 They also showed no sign of autocorrelation when tested. 
series themselves ${ }^{16}$. This is confirmed by Table 5 , which presents summary statistics of sectoral outputs and their two components. Recall the decomposition of sectoral output presented in equation (2.15): $y_{i t}=y_{i s}^{p}+y_{i r}^{e}, \quad \forall i$. Because $\operatorname{VAR}\left(y_{i t}\right)=\operatorname{VAR}\left(y_{i t}^{p}\right)+\operatorname{VAR}\left(y_{i t}^{c}\right)+2 \cdot \operatorname{COV}\left(y_{i r}^{p}, y_{i t}^{c}\right), \quad \forall i$, whenever the covariance between trend and cycle is negative and big in absolute value, individual sectoral GNP's may be smoother than their respective trends. Thus, what explains the relative volatility of the trend here is its negative correlation with the cycle. Notice that this particular result is found in applications of the univariate Beveridge-Nelson decomposition as well.

Recall from section 2, that the estimated cycles are a linear combination of the Error Correction terms $\left(Z_{i s}=\alpha_{i}^{\prime} y_{s}, \quad i=1,2\right)$. Thus, examining the $Z$ 's may shed light on the behavior of the cycles. A plot of the two Z's is presented in Figure 12, which includes NBER recessions ${ }^{17}$. Even though $Z_{1}$ is basically flat, $Z_{2}$ displays a typical cyclical behavior, decreasing in every single post-war recession. The cyclical components of sectoral output series are plotted in Figures 13 through 16, which also include NBER recessions. In these plots, sectors are grouped according to the similarity of their cycles. Five out of eight sectoral cycles conform to NBER recessions and are therefore labelled pro-cyclical. They are: Mining, Manufacturing, Wholesale/Retail Trade and Finance. Three sectors do not conform with NBER recessions, with upward movements during those, and are labelled counter-cyclical. They are: Agriculture, Transportation and Services.

16 It should be noted that this feature is not a general consequence of the methodology used. since the trend in the Wholesale/Retail Trade sector is smoother than that sectoral output itself. 17 There is a mismatch of frequency between our data and the NBER methodology, which works with monthly observations. For our purposes, recession years are the following: 1948-49. $1953-54,1957-58,1960-61,1969-70,1973-75$ and 1980-82. 
Examining the cycles of pro-cyclical sectors reveals that these have similar shapes and durations but very different amplitudes. The sector with the cycle of highest amplitude is Construction. This is not surprising: since Construction includes housing construction, our evidence is in line with the stylized facts in Lucas(1977), who points out that consumer durable output has a relative high amplitude. Construction is followed by Mining and Manufacturing, with amplitudes roughly half its size. Finally, the lowest amplitudes are found for Wholesale/Retail Trade and Finance, with amplitudes roughly a fifth of that of Construction.

All the counter-cyclical sectors have very similar cycles in shape and duration. They also share in common a very small amplitude. Moreover, it seems that the shape of these counter-cyclical cycles is just an upside down version of the pro-cyclical ones. These findings reinforce the idea that per-capita sectoral outputs have a common cycle, if not in the statistical sense at least in the economic sense. The plot of the EC terms ( $Z$ 's) only reinforced this suspicion, since only one of the (Z's) has a business cycle behavior.

To investigate further the findings of counter-cyclical sectors, a plot of the (log) level series for these sectors is presented in Figure 17, which includes NBER recessions. During recessions, the behavior of Agriculture is definitely odd: while its series is almost flat, it increased in four out of seven recessions. Likewise, Services displays little downward sensitivity in recession periods, which is most striking until the 1969-70 recession. Until then, not only per-capita Services output increased during recessions but it showed no decrease in its growth rate vis-a-vis neighboring periods. After 1970, this feature is reversed. Transportation is the only counter-cyclical series which does not display any unusual behavior for recession periods. In that sense, finding it to have a counter-cyclical behavior is surprising.

There is some empirical support for our findings of counter-cyclical sectors: using PSID data, Lougani and Rogerson(1989) found that the inflow of workers into Services increases 
during recessions and that the outflow of workers from Services increases during booms. These findings are consistent with counter-cyclical behavior for Services, even though they do not imply it. For Agriculture, Romer(1991), using factor analysis, found evidence that several agricultural goods have short run counter-cyclical behavior (see p 27). Even though her evidence is more compelling for the inter-war era, it holds for the post-war era as well. Evidence of low coherence for agricultural output is also mentioned in Lucas(1977) as a stylized fact of business cycles (see section 2 ).

Finding counter-cyclical sectors is a way of conciliating the business cycle evidence of persistence and comovement for sectoral outputs with the sectoral shifts evidence. If sectoral outputs were $I(0)$, persistence and comovement of sectoral outputs would imply a positive correlation among them. On the other hand, sectoral shifts would imply a negative correlation among sectoral outputs, since some sectors are hit with positive shocks and others with negative shocks. These mutually exclusive possibilities may cease in an I(1) world: in this case, we can allow counter-cyclical sectors to account for sectoral shifts, while keeping a high positive correlation in levels of sectoral outputs to account for persistence and comovement. In a trending world, this last result is achieved simply because trend components dominate the correlation coefficient in levels.

The next exercise done was a variance decomposition of trend and cycle innovations (one step ahead forecast errors). The results are presented in Tables 6, 7A and 7B. It is useful to explain the method used to identify trend and cycle innovations before discussing these results. For trend innovations recall equation (2.17): since $\bar{\alpha}^{\prime} \Delta y_{s}$ is white noise, $\bar{\alpha}^{\prime} y_{3}$ is a random walk. This implies that $\tilde{a} \tilde{\alpha}^{\prime} y$, is also a random walk, since it is a linear combination of random walks. As a result, $y_{t}^{f}$ is a random walk plus a constant and a deterministic trend, and its innovation can be found by first differencing it. For cycle innovations recall equation (2.16): since $y_{c}^{c}$ is a linear 
combination of the detrended EC terms, we can find cyclical innovations by running sectoral cycles on lagged detrended EC terms ${ }^{18}$. We chose to include up to four lags of the EC terms in calculating cyclical innovations.

Table 6 presents the results of the variance decomposition of total sectoral innovations (trend plus cycle). Their striking characteristic is the following: innovations in the trend and in the cycle are negatively correlated for almost all sectors. The only exception is Wholesale/Retail Trade, for which they are uncorrelated. As stressed in the theoretical macro literature, e.g., King, Plosser and Rebelo(1988a,b), a shock changing the steady states of integrated control variables also triggers short run dynamics leading towards these new steady states. Thus, one should expect trend and cycle innovations to be correlated in general. An interesting result is that almost all trend and cycle innovations are negatively correlated. Thus, for almost all sectors, the effect of a $1 \%$ increase in the trend innovation will only lead to a $1 \%$ increase in the level of sectoral output in the long run, since the short run dynamics inhibits its full impact. Similar results are reported in the simulations of King, Plosser and Rebelo(1988b) (see p 315, Figure 1) and are achieved by the theoretical model of King, Plosser, Stock and Watson $(1987)^{19}$.

18 This is only one possible way of finding sectoral innovations. Another appealing choice involves using the EC representation in the following way: pre-multiply (2.6) by $\alpha^{\prime}$ and rearrange to get:

$Z_{t}=\left(\alpha^{\prime} \gamma-I\right) Z_{t-1}+\sum_{i=1}^{k-1} \alpha^{\prime} A_{i}^{*} \Delta y_{t-i}+\alpha^{\prime} \mu_{0}+\alpha^{\prime} \mu_{1} \cdot t+\alpha^{\prime} \varepsilon_{s}$

Where $Z_{t}=\alpha^{\prime} y_{t}$. Thus, a natural way of calculating cyclical innovations is to run cycles on lagged detrended $Z$ 's and lagged $\Delta y_{f}$ 's. This altemative however did not provide serially uncorrelated estimates and was therefore dropped.

19 We cite the preliminary version here since part of the theoretical model is supressed from the published version. 
It is very hard to infer the importance of trend and cycle innovations from the results of Table 6, since for almost all sectors the covariance effect is very large. The only case of orthogonal innovations is Wholesale/Retail Trade, for which the cyclical innovation accounted for roughly $80 \%$ of total sectoral innovation variance. In order to be able to pursue this relevant issue further, we used principal components in orthogonalizing the covariance matrix of trend and cyclical innovations ${ }^{20}$. Tables $7 \mathrm{~A}$ and $7 \mathrm{~B}$ present the results of this exercise. It is clear looking at these Tables that the ordering of innovations really changes the type of results achieved: in Table 7A, where we ordered the trend innovation first, the cyclical innovation is assigned the bulk of the variance for most sectors. The opposite result is shown in Table 7B, where that ordering was reversed.

Despite the difference in results shown in Tables $7 \mathrm{~A}$ and $7 \mathrm{~B}$, some sectors displayed remarkable robustness to the changes in the ordering of innovations. For example, the results for Wholesale/Retail Trade were kept in line with those of Table 6, with the cycle innovation explaining from $70 \%-80 \%$ of total innovation. Manufacturing is another example of the bulk of total variance explained by cycle innovations: $60 \%-100 \%$. Sectors where trend innovations are unequivocally important are: Agriculture, with 70\%-100\%, Transportation, with 70\%-90\%, and Services, with $40 \%-100 \%$. Notice that these are the counter-cyclical sectors. The remaining sectors, Construction, Mining and Finance, have results that seem to depend heavily on the ordering of innovations used, thus remaining open issues. The picture that emerges from these analyses is that there is no clear evidence that either trend or cyclical innovations have a prominent role across all sectors. However, for essential sectors like Manufacturing and Wholesale/Retail Trade, cycle innovations do have a prominent role.

20 See notes on Tables $7 \mathrm{~A}$ and $7 \mathrm{~B}$ for details. 
Our evidence from the variance decomposition exercise is very different from the one presented in King, Plosser, Stock and Watson(1991). In their RBC model, the trend innovation explained the bulk of the variance of total output innovation. There are two possible explanations for the difference in results: first, we are using disaggregated data, and second we are using a different methodology in performing the trend-cycle decomposition.

\section{Conclusions and Further Research}

The basic goal of this paper was to re-examine business cycles using a modem econometric technique which allows for modelling integrated time series with both short and long run comovement. The results of applying this technique to per-capita sectoral output data revealed that these share a relatively large number of common trends but a relatively low number of common cycles. Thus, trends in per-capita sectoral outputs have a very distinct behavior, whereas cycles seem almost identical in shape, duration and timing. This evidence is in accordance with the belief implicit in Bums and Mitchell(1946) that most economic series are driven by a common cycle.

The fact that cycles are so similar for different sectors is remarkable evidence, which confirms the basic thrust of Burns and Mitchell(1946). Notice that this result was obtained using modem econometric techniques, able to discuss business cycles while accommodating I(1) cointegrated series. Since for I(1) series the trend component is the only one to have asymptotic infinite variance, the results of the variance decomposition were surprising, as they showed that for prominent sectors such as Manufacturing and Wholesale/Retail Trade, cyclical innovations were the most important in explaining total innovations. This result casts doubt in the recent direction of the RBC literature, where trends and permanent shocks seem to have a prominent role and cycles and temporary shocks a secondary one. 
The results of our trend-cycle decomposition also revealed that trend and cycle innovations are negatively correlated. As it seems, a positive shock to the trend has two effects: it sends the permanent component up, increasing the steady state value for sectoral ourputs, but also sends the cycle down. This result is in line with the simulations in King, Plosser and Rebelo(1988b). This negative correlation opens the possibility for purely temporary shocks to sectoral outputs to have permanent effects on these variables. In this richer environment, long and shor run get integrated, since long run shocks can cause economic fluctuations and shor run shocks can have permanent effects. This result is in line with the discussion in Prescott(1986), who claims it is inadequate to model trends and cycles in a dichotomous way. In this scenario, economic policy deserves a closer look, since until today macroeconomists have isolated long and short run policy effects.

The final picture that emerges from our evidence on sectoral ourputs is that of idiosyncratic trends and similar cycles. For sectors like Agriculture, Transportation and Services it seems that the trend component is the most important. However, for Manufacturing and Wholesale/Retail Trade, it seems that the cycle is the most imporant. Even though the theoretical RBC literature has gone very far in modelling together economic growth and fluctuations under optimizing models, little empirical evidence have accumulated supporting these models, especially with regard to linking long run shocks to technology. With that regard, our extended model offers an empirical test for Real Business Cycles, since it suggests that the cointegrating rank of productivity shocks and sectoral outputs should coincide. Further research should try to close the present gap between the RBC literature and empirical evidence. 


\section{References}

Anderson, T.W.(1984); "An Introduction to Multivariate Statistical Analysis". New York, Wiley.

Beveridge, S. and Nelson, C.R.(1981); "A new Approach to Decomposition of Economic Time Series into a Permanent and Transitory Components with Particular Attention to Measurement of the "Business Cycle"." Journal of Monetary Economics, vol. 7 , pp 151-174.

Blanchard, O.J. and Quah, D.(1989); "The Dynamic Effects of Aggregate Supply and Demand Disturbances." American Economic Review, vol. 79, pp 655-673.

Blanchard, O.J. and Watson M.W.(1986); "Are Business Cycles All Alike?" In American Business Cycles: Continuity and Change. Edited by Robert J. Gordon. University of Chicago Press.

Burns, A.F. and Mitchell, W.C.(1946); "Measuring Business Cycles." New York: National Bureau of Economic Research.

Campbell, J.Y. and Mankiw, N.G.(1987); "Permanent and Transitory Components in Macroeconomic Fluctuations." American Economic Review, May 1987.

Cochrane, J.H.(1991); "Univariate vs. Multivariate Forecasts of GNP and Stock Returns: Evidence and Implications for the Persistence of Shocks, Detrending Methods, and Tests of the Permanent Income Hypothesis." Paper presented on February 1991 in the NBER meeting on Economic Fluctuations. Mimeo.

Durlauf, S.N.(1989); "Output Persistence, Economic Structure, and the Choice of Stabilization Policy." Brookings Papers in Economic Activity, vol. 2, pp 69-136.

Engle, R.F. and Granger, C.W.J.(1987); "Cointegration and Error Correction: Representation, Estimation and Testing." Econometrica, vol. 55, pp 251-276.

Engle, R.F. and Kozicki, S.(1990); "Testing for Common Features." Working Paper, University of California San Diego.

Granger, C.W.J.(1983); "Co-integrated Variables and Error Correcting Models." UCSD discussion paper 88-13a. Unpublished manuscript.

Granger, C.W.J.(1986); "Developments in the Study of Cointegrated Variables." Oxford Bulletin of Economics and Statistics, vol. 48, pp 213-228.

Johansen, S.(1988); "Statistical Analysis of Cointegrating Vectors." Journal of Economic Dynamics and Control, vol. 12, 231-254.

Johansen, S.(1991a); "Estimation and Hypothesis Testing of Cointegration Vectors in Gaussian Vector Autoregressive Models." Econometrica, vol. 59, pp 1551-1580.

Johansen, S.(1991b); "Estimating Systems of Trending Variables." Lecture presented at the ESEM 1991, Cambridge, U.K. Unpublished manuscript, University of Copenhagen.

King, R.G., Plosser, C.I. and Rebelo, S.(1988a); "Production, Growth and Business Cycles. I. The basic Neoclassical Model." Journal of Monetary Economics, vol. 21, pp 195-232.

King, R.G., Plosser, C.I. and Rebelo, S.(1988b); "Production, Growth and Business Cycles. II. New Directions." Journal of Monetary Economics, vol. 21, pp 309-341. 
King, R.G., Plosser, C.I., Stock, J.H. and Watson, M.W.(1987); "Stochastic Trends and Economic Fluctuations." Paper presented at the NBER meeting on Economic Fluctuations, Stanford, U.S. Preliminary version.

King, R.G., Plosser, C.I., Stock, J.H. and Watson, M.W.(1991); "Stochastic Trends and Economic Fluctuations." American Economic Review, vol. 81, pp 819-840.

Kydland, F. and Prescott, E.(1982); "Time to Build and Aggregate Fluctuations." Econometrica, vol. 50, pp 1345-1370.

Lancaster, P.(1969); "The Theory of Matrices." New York: Academic Press.

Lilien, D.M.(1982); "Sectoral Shifts and Cyclical Unemployment." Journal of Political Economy, vol. 90, pp 777-793.

Long, J.B. and Plosser, C.I.(1983); "Real Business Cycles." Journal of Political Economy, vol.91, pp 39-69.

Long, J.B. and Plosser, C.I.(1987); "Sectoral vs. Aggregate Shocks in the Business Cycles." American Economic Review, May 1987.

Lougani, P. and Rogerson, R.(1989); Cyclical Fluctuations and Sectoral Reallocation: Evidence from PSW." Journal of Monetary Economics, vol. 23, pp 259-273.

Lucas, R.E., Jr.(1977); "Understanding Business Cycles." Carnegie-Rochester Conference Series on Public Policy, vol. 5, pp 7-29. Amstendam: North Holland.

Mankiw, N.G.(1989); "Real Business Cycles: A New Keynesian Perspective." Journal of Economic Perspectives, vol. 3, pp 79-90.

Nelson, C.R. and Kang, H.(1981); "Spurious Periodicity in Inappropriately Detrended Time Series." Econometrica, vol. 49, pp 741-751.

Nelson, C.R. and Kang, H.(1984); "Pitfalls in the Use of Time as an Explanatory Variable in Regression." Journal of Business and Economic Statistics, vol. 2, pp 73-82.

Nelson, C.R. and Plosser, C.I.(1982); "Trends and Random Walks in Macroeconomic Time Series." Journal of Monetary Economics, vol. 10, pp 139-162.

Prescott, E.C.(1986); "Theory Ahead of Business-Cycle Measurement." Carnegie-Rochester Conference Series on Public Policy, vol. 25, pp 11-44. Amsterdam: North Holland.

Ramey, V.A.(1988); "Money, Trade Credit, and Output: A Test of the Real Business Cycle Hypothesis." Working Paper, University of California San Diego.

Rao, C.R.(1973); "Linear Statistical Inference." New York, Wiley.

Rogerson, R.(1987); "An Equilibrium Model of Sectoral Reallocation." Jourmal of Political Economy, vol. 95, pp 824-834.

Romer, C.D.(1991); "The Cyclical Behavior of Individual Production Series." Quarterly Journal of Economics, vol. 106, pp 1-31.

Stock, J.H. and Watson, M.W.(1988); "Testing for Common Trends." Journal of the American Statistical Association, vol. 83, pp 1097-1107.

Stockman, A.C.(1988); "Sectoral and National Aggregate Disturbances to Industrial Output in Seven European Countries." Journal of Monetary Economics, vol. 21. 
Stockman, A.C. and Tesar, L.L.(1990); "Tastes and Technology in a Two Country Model of Business Cycle: Explaining Intemational Comovement." Working Paper, University of Rochester.

Vahid, F. and Engle, R.F.(1992); "Common Trends and Common Cycles." University of California at San Diego, mimeo.

Watson, M.W.(1986); "Univariate Detrending Methods with Stochastic Trends." Journal of Monetary Economics, vol. 18, pp 49-75. 


\section{Appendix}

Proof of Proposition 3.1: There is cointegration among the $\log (\mathrm{Y})$ 's if and only if $A(1)=(I-A)(I-\Phi)$ is reduced rank. Recall the constant retums to scale assumption on production functions:

$\sum_{j=1}^{N} a_{i j}+b_{i}=1 \forall i$

and $a_{i j} \geq 0$.

If labor is used in all production processes, $b_{i}>0 \quad \forall i$, thus:

$\sum_{j=1}^{N} a_{i j}<1 \quad \forall i$

and $a_{i j} \geq 0$.

Therefore, $\mathbf{A}=\left(a_{i j}\right)$ is a non-negative matrix. Consider now, $(I-A)$. Its eigenvalues are:

$1-\lambda_{1}^{A}, \quad 1-\lambda_{2}^{A}, \ldots, \quad 1-\lambda_{N}^{A}$, where $\lambda_{1}^{A}, \quad \lambda_{2}^{A}, \ldots, \quad \lambda_{N}^{A}$, are the eigenvalues of $A$. Clearly, since $A(1)=(I-A)(I-\Phi)$, if $(I-A)$ is full rank, $\mathrm{A}(1)$ is full rank if and only if $(I-\Phi)$ is full rank. To prove that $(I-A)$ is full rank, it suffices to show that:

$\max _{i}\left|\lambda_{i}^{A}\right|<1$

Since it implies that all eigenvalues of $(I-A)$ are non-zero. Equation (A.1) follows from a theorem relating matrix norms and spectral radius, see Lancaster(1969), Theorem 6.13, p 201. Define:

$\|A\|_{\rho} \equiv \max _{i} \sum_{j=1}^{N}\left|a_{i j}\right|$

To be the row norm of A. Lancaster(1969), Theorem 6.13, says that:

$\|A\|_{\rho} \geq \max _{i}\left|\lambda_{i}^{A}\right|$.

Since $0 \leq \sum_{j=1}^{N}\left|a_{i j}\right|<1 \quad \forall i,\|A\|_{p}<1$. Thus: $\max _{i}\left|\lambda_{i}^{A}\right|<1$, and $(I-A)$ is full rank. Therefore, $A(1)$ is reduced rank if and only if $(I-\Phi)$ is reduced rank. Moreover, $\operatorname{rank}(A(1))=\operatorname{rank}(I-\Phi)$, and the result follows. 
TABLE 1

COINTEGRATING RESULTS (JOHANSEN'S(1988) METHOD)

\begin{tabular}{|c|c|c|c|}
\hline $\begin{array}{c}\text { EIGENVALUES } \\
\left(\mu_{i}\right)\end{array}$ & $\begin{array}{c}\text { TRACE STAT. } \\
-T \sum_{j \leq i} \ln \left(1-\mu_{j}\right)\end{array}$ & $\begin{array}{c}\text { CRITICAL VALUE } \\
\text { AT 5\% }(1 \%)\end{array}$ & NULL HYPOTHESES \\
\hline 0.0066 & 0.27 & $\begin{array}{c}4.95 \\
(6.65)\end{array}$ & $\begin{array}{c}\exists \text { at most } 7 \\
\text { cointegrating vectors }\end{array}$ \\
\hline 0.1517 & 7.02 & $\begin{array}{c}17.52 \\
(20.03)\end{array}$ & $\begin{array}{c}\exists \text { at most } 6 \\
\text { cointegrating vectors }\end{array}$ \\
\hline 0.2303 & 17.75 & $\begin{array}{c}32.55 \\
(35.65)\end{array}$ & $\begin{array}{c}\exists \text { at most } 5 \\
\text { cointegrating vectors }\end{array}$ \\
\hline 0.3509 & 35.47 & $\begin{array}{c}50.34 \\
(54.46)\end{array}$ & $\begin{array}{c}\exists \text { at most } 4 \\
\text { cointegrating vectors }\end{array}$ \\
\hline 0.4576 & 60.55 & $\begin{array}{c}71.80 \\
(76.06)\end{array}$ & $\begin{array}{c}\exists \text { at most 3 } \\
\text { cointegrating vectors }\end{array}$ \\
\hline 0.5762 & 95.75 & $\begin{array}{c}98.33 \\
(103.18)\end{array}$ & $\begin{array}{c}\exists \text { at most 2 } \\
\text { cointegrating vectors }\end{array}$ \\
\hline 0.7599 & 154.25 & $\begin{array}{c}128.44 \\
(133.57)\end{array}$ & $\begin{array}{c}\exists \text { at most 1 } \\
\text { cointegrating vectors }\end{array}$ \\
\hline 0.8976 & 247.69 & $\begin{array}{c}161.31 \\
(168.35)\end{array}$ & $\begin{array}{c}\exists \text { at most 0 } \\
\text { cointegrating vectors }\end{array}$ \\
\hline
\end{tabular}


TABLE 2

SYSTEM ESTMMATES OF THE EC MODEL DEPENDENT VARIABLES

\begin{tabular}{|c|c|c|c|c|c|c|c|c|}
\hline REGRESSORS & $\Delta \log A_{1}$ & $\Delta \log \operatorname{Con}$ & $\Delta \log \mathrm{Min}$ & $\Delta \log _{\mathrm{B}} M_{\mathrm{r}}$ & $\Delta \log T_{i}$ & $\Delta \log W_{1}$ & $\Delta \log F_{r}$ & $\Delta \log S_{t}$ \\
\hline$\underset{\text { t-stat. }}{Z_{1 / 2}}$ & $\begin{array}{r}1.47 \\
(1.48)\end{array}$ & $\begin{array}{r}0.09 \\
(0.13)\end{array}$ & $\begin{array}{r}-1.57 \\
(-1.79)\end{array}$ & $\begin{array}{r}-2.47 \\
(-2.43)\end{array}$ & $\begin{array}{r}-0.73 \\
(-1.39)\end{array}$ & $\begin{array}{r}-0.96 \\
(-1.88)\end{array}$ & $\begin{array}{r}-0.67 \\
(-2.95)\end{array}$ & $\begin{array}{r}-0.67 \\
(-259)\end{array}$ \\
\hline 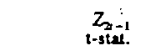 & $\begin{array}{r}0.08 \\
(1.67)\end{array}$ & $\begin{array}{r}-0.04 \\
(-1,20)\end{array}$ & $\begin{array}{r}-0.02 \\
(-0.39)\end{array}$ & $\begin{array}{r}-0.05 \\
(-0.95)\end{array}$ & $\begin{array}{r}-0.02 \\
(-0.77)\end{array}$ & $\begin{array}{r}-0.06 \\
(-2.56)\end{array}$ & $\begin{array}{r}0.01 \\
(0.54)\end{array}$ & $\begin{array}{r}-0.03 \\
(-2.52)\end{array}$ \\
\hline$\underset{\text { T-stat. }}{\text { TREND }}$ & $(2.93)$ & $\begin{array}{r}0.00 \\
(-0.49)\end{array}$ & $\begin{array}{r}0,000 \\
(-1.39)\end{array}$ & $(-2.00)$ & $\begin{array}{r}0.00 \\
(-3.04)\end{array}$ & $\begin{array}{r}0.00 \\
(-0.88)\end{array}$ & $\begin{array}{r}0.00 \\
(-4.59)\end{array}$ & $\begin{array}{r}0.00 \\
(-0.42)\end{array}$ \\
\hline$\underset{\text { i-stal. }}{\Delta \log A_{t-1}}$ & $\begin{array}{r}-0.64 \\
(-3.20)\end{array}$ & $\begin{array}{r}-0.02 \\
(-0.17)\end{array}$ & $\begin{array}{r}-0.26 \\
(-1.45)\end{array}$ & $\begin{array}{r}0.05 \\
(0.24)\end{array}$ & $\begin{array}{r}0.16 \\
(1.55)\end{array}$ & $\begin{array}{r}-0.07 \\
(-0.69)\end{array}$ & $\begin{array}{r}0.03 \\
(0.62)\end{array}$ & $\begin{array}{r}-0.04 \\
(-0.79)\end{array}$ \\
\hline$\Delta \log _{i} \operatorname{Con}_{\text {int }}$ & $\begin{array}{r}0.58 \\
(1.74)\end{array}$ & $\begin{array}{r}0.16 \\
(0.70)\end{array}$ & $\begin{array}{r}-0.26 \\
(-0.90)\end{array}$ & $\begin{array}{r}-0.21 \\
(-0.61)\end{array}$ & $\begin{array}{r}-0.22 \\
(-1.28)\end{array}$ & $\begin{array}{r}-0.35 \\
(-2.07)\end{array}$ & $\begin{array}{r}-0.06 \\
(-0.78)\end{array}$ & $\begin{array}{r}-0.09 \\
(-1.02)\end{array}$ \\
\hline$\Delta \log \operatorname{Min}_{\text {t-stat. }}$ & $\begin{array}{r}0.89 \\
2.97)\end{array}$ & $\begin{array}{r}0.11 \\
(0.55)\end{array}$ & $\begin{array}{c}-0.22 \\
(-0.85)\end{array}$ & $\begin{array}{r}-0.22 \\
(-0.73)\end{array}$ & $\begin{array}{r}-0.17 \\
(-1.11)\end{array}$ & $\begin{array}{r}0.28 \\
(1.80)\end{array}$ & $\begin{array}{r}-0.11 \\
(-1.62)\end{array}$ & $\begin{array}{r}-0.13 \\
(-1.62)\end{array}$ \\
\hline$\Delta \log _{t-s t a t} M_{1-1}$ & $\begin{array}{r}-0.29 \\
(-0.81)\end{array}$ & $\begin{array}{r}-0.38 \\
(-1.56)\end{array}$ & $\begin{array}{r}0.17 \\
(0.54)\end{array}$ & $\begin{array}{r}-0.16 \\
(-0.45)\end{array}$ & $\begin{array}{r}-0.25 \\
(-1.33)\end{array}$ & $\begin{array}{r}-0.37 \\
(-1.99)\end{array}$ & $\begin{array}{r}-0.07 \\
(-0.80)\end{array}$ & $\begin{array}{r}0.05 \\
(0.56)\end{array}$ \\
\hline 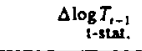 & $\begin{array}{r}-0.37 \\
(-0.40)\end{array}$ & $\begin{array}{r}0.11 \\
(0.18)\end{array}$ & $\begin{array}{r}-1.70 \\
(-2.05)\end{array}$ & $\begin{array}{r}-1.93 \\
(-2.01)\end{array}$ & $\begin{array}{r}-0.29 \\
(-0.59)\end{array}$ & $\begin{array}{r}-0.83 \\
(-1.72)\end{array}$ & $\begin{array}{r}-0.23 \\
(-1.09)\end{array}$ & $\begin{array}{r}-0.59 \\
(-2.40)\end{array}$ \\
\hline$\Delta \underset{\text { t-stal. }}{\Delta \log W_{1-1}}$ & $\begin{array}{r}-0.62 \\
(-0.71)\end{array}$ & $\begin{array}{r}0.19 \\
(0.31)\end{array}$ & $\begin{array}{r}1.45 \\
(1.86)\end{array}$ & $\begin{array}{r}2.66 \\
2.95)\end{array}$ & $\begin{array}{r}1.13 \\
(2.43)\end{array}$ & $\frac{1.22}{(2.69)}$ & $\begin{array}{r}0.55 \\
(2.74)\end{array}$ & $\begin{array}{r}0.58 \\
(2.53)\end{array}$ \\
\hline$\underset{\text { t-stal. }}{\Delta \log F_{t-1}}$ & $\begin{array}{r}0.10 \\
(0.11)\end{array}$ & $\begin{array}{r}-0.99 \\
(-0.97)\end{array}$ & $\begin{array}{r}1.11 \\
(1.39)\end{array}$ & $\begin{array}{r}-0.30 \\
(-0.32)\end{array}$ & $\begin{array}{r}0.24 \\
(0.50)\end{array}$ & $\begin{array}{r}0.65 \\
(1.39)\end{array}$ & $\begin{array}{r}-0.32 \\
(-1.54)\end{array}$ & $\begin{array}{r}0.40 \\
(1.68)\end{array}$ \\
\hline$\underset{t-2 t a t .}{\Delta \log S_{t-1}}$ & $\begin{array}{r}-0.98 \\
(-1.08)\end{array}$ & $\begin{array}{r}1.12 \\
(1.82)\end{array}$ & $\begin{array}{r}1.08 \\
(1.35)\end{array}$ & $\begin{array}{r}2.24 \\
(2.40)\end{array}$ & $\begin{array}{r}1.47 \\
(3.06)\end{array}$ & $\begin{array}{r}0.84 \\
(1.79)\end{array}$ & $\begin{array}{r}0.74 \\
(3.58)\end{array}$ & $\begin{array}{r}0.87 \\
(3.67) \\
\end{array}$ \\
\hline$\Delta \log _{\text {t-stat. }} A_{t-2}$ & $\begin{array}{r}-0.23 \\
(-1.08)\end{array}$ & $\begin{array}{r}0.04 \\
(0.29)\end{array}$ & $\begin{array}{r}0.00 \\
(0.02)\end{array}$ & $\begin{array}{r}0.47 \\
(2.11)\end{array}$ & $\begin{array}{r}0.30 \\
(2.65)\end{array}$ & $\begin{array}{r}0.10 \\
(0.92)\end{array}$ & $\begin{array}{r}0.10 \\
(2.06)\end{array}$ & $\begin{array}{r}0.06 \\
(1.14)\end{array}$ \\
\hline$\underset{\text { t-stat. }}{\Delta \log _{2} \mathrm{Con}_{4}}$ & $\begin{array}{r}0.29 \\
(1.07)\end{array}$ & $\begin{array}{r}0.34 \\
(1.89)\end{array}$ & $\begin{array}{r}-0.42 \\
(-1.77)\end{array}$ & $\begin{array}{r}-0.40 \\
(-1.45)\end{array}$ & $\begin{array}{r}0.28 \\
(-1.96)\end{array}$ & $\begin{array}{r}-0.03 \\
(-0.21)\end{array}$ & $\begin{array}{r}0.00 \\
(0.08)\end{array}$ & $\begin{array}{r}-0.12 \\
(-1.66)\end{array}$ \\
\hline 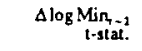 & $\begin{array}{r}0.36 \\
(0.97)\end{array}$ & $\begin{array}{r}0.02 \\
(0.09)\end{array}$ & $\begin{array}{r}-0.57 \\
(-1.73)\end{array}$ & $\begin{array}{r}-0.99 \\
(-2.60)\end{array}$ & $\begin{array}{r}-0.49 \\
(-252)\end{array}$ & $\begin{array}{r}-0.30 \\
(-1.58)\end{array}$ & $\begin{array}{r}-0.20 \\
(-2.36)\end{array}$ & $\begin{array}{r}-0.09 \\
(-0.94)\end{array}$ \\
\hline$\underset{\text { t-stat. }}{\Delta \log M_{t}}$ & $\begin{array}{r}-0.69 \\
(-1.61)\end{array}$ & $\begin{array}{r}0.38 \\
(1.32)\end{array}$ & $\begin{array}{r}0.85 \\
(2.24)\end{array}$ & $\begin{array}{r}1.49 \\
(3.40)\end{array}$ & $\begin{array}{r}0.71 \\
(3.16)\end{array}$ & $\begin{array}{r}0.69 \\
(3.17)\end{array}$ & $\begin{array}{r}0.34 \\
(3.46)\end{array}$ & $\begin{array}{r}0.12 \\
(1.10) \\
\end{array}$ \\
\hline$\underset{\text { l-stat. }}{\Delta \log T_{1-2}}$ & $\begin{array}{r}0.87 \\
(1.31)\end{array}$ & $\begin{array}{r}-0.43 \\
(-0.98)\end{array}$ & $\begin{array}{r}-1.04 \\
(-1.79)\end{array}$ & $\begin{array}{r}-0.74 \\
(-1.10)\end{array}$ & $\begin{array}{r}-0.38 \\
(-1.08)\end{array}$ & $\begin{array}{r}-0.44 \\
(-1.31)\end{array}$ & $\begin{array}{r}-0.28 \\
(-1.84)\end{array}$ & $(-0.24)$ \\
\hline$\underset{t-s i a d:}{\Delta \log W_{t-2}}$ & $\begin{array}{r}-0.01 \\
(-0.03)\end{array}$ & $\begin{array}{r}-0.49 \\
(-1.69)\end{array}$ & $\begin{array}{r}0.77 \\
(2.03)\end{array}$ & $\begin{array}{r}0.22 \\
(0.51)\end{array}$ & $\begin{array}{r}0.07 \\
(0.32)\end{array}$ & $\begin{array}{r}0.16 \\
(0.73)\end{array}$ & $\begin{array}{r}-0.05 \\
(-0.48)\end{array}$ & $\begin{array}{r}0.32 \\
(.8 .85)\end{array}$ \\
\hline$\Delta \underset{\text { t-stat. }}{\Delta \log F_{1-2}}$ & $\begin{array}{r}1.03 \\
(0.97)\end{array}$ & $\begin{array}{r}-1.06 \\
(-1.49)\end{array}$ & $\begin{array}{r}-1.07 \\
(-1.15)\end{array}$ & $\begin{array}{r}-3.51 \\
(\cdot 3.24)\end{array}$ & $\begin{array}{r}-1.63 \\
(-2.92)\end{array}$ & $\begin{array}{r}-1.80 \\
(-3.32)\end{array}$ & $\begin{array}{r}-0.70 \\
(-2.89)\end{array}$ & $\begin{array}{r}-0.27 \\
(-0.96)\end{array}$ \\
\hline$\Delta \log S_{1-2}=$ & $\begin{array}{r}-0.01 \\
(-0.01)\end{array}$ & $\begin{array}{r}-1.41 \\
(-2.61)\end{array}$ & $\begin{array}{r}-0.87 \\
(-1.22)\end{array}$ & $\begin{array}{r}-1.46 \\
(-1.76)\end{array}$ & $\begin{array}{r}-0.40 \\
(-0.94)\end{array}$ & $\begin{array}{r}-0.57 \\
(-1.38)\end{array}$ & $\begin{array}{r}-0.33 \\
(-1.77)\end{array}$ & $\begin{array}{r}-0.34 \\
(-1.63)\end{array}$ \\
\hline
\end{tabular}


TABLE 3

SYSTEM SIGNIFICANCE TESTS (EC MODEL)

\begin{tabular}{|c|c|c|c|c|c|c|}
\hline \multicolumn{7}{|c|}{ F-STATISTIC ON RETAINED REGRESSORS $F(8,20)$} \\
\hline REGRESSOR & $Z_{1 f-1}$ & $Z_{21-1}$ & TREND & $\Delta \log A_{t-1}$ & $\Delta \log \operatorname{Con}_{t-1}$ & $\Delta \log \operatorname{Min}_{r-1}$ \\
\hline$\underset{P}{F}=F$ & $\begin{array}{l}17.26 \\
.0000\end{array}$ & $\begin{array}{l}2.55 \\
.0427\end{array}$ & $\begin{array}{l}7.02 \\
.0002\end{array}$ & $\begin{array}{l}1.71 \\
.1587\end{array}$ & $\begin{array}{c}2.67 \\
.0360\end{array}$ & $\begin{array}{l}4.11 \\
.0049\end{array}$ \\
\hline REGRESSOR & $\Delta \log M_{t-1}$ & $\Delta \log T_{t-1}$ & $\Delta \log W_{t-1}$ & $\Delta \log F_{t-1}$ & $\Delta \log S_{t-1}$ & $\Delta \log A_{t-2}$ \\
\hline $\begin{array}{c}F \\
P T>F\end{array}$ & $\begin{array}{r}6.26 \\
.0004 \\
\end{array}$ & $\begin{array}{c}8.68 \\
.0000 \\
\end{array}$ & $\begin{array}{l}6.31 \\
.0004 \\
\end{array}$ & $\begin{array}{c}3.38 \\
.0128 \\
\end{array}$ & $\begin{array}{c}1.62 \\
.1810\end{array}$ & $\begin{array}{c}1.62 \\
.1807\end{array}$ \\
\hline REGRESSOR & $\Delta \log \operatorname{Con}_{t-2}$ & $\Delta \log \mathrm{Min}_{t-2}$ & $\Delta \log M_{i-2}$ & $\Delta \log T_{t-2}$ & $\Delta \log W_{t-2}$ & $\Delta \log F_{1-2}$ \\
\hline$\underset{P r>F}{F}$ & $\begin{array}{c}2.36 \\
.0568 \\
\end{array}$ & $\begin{array}{l}2.68 \\
.0353 \\
\end{array}$ & $\begin{array}{l}4.07 \\
.0051\end{array}$ & $\begin{array}{c}1.81 \\
.1348\end{array}$ & $\begin{array}{c}5.51 \\
.0009 \\
\end{array}$ & $\begin{array}{r}2.40 \\
.0541 \\
\end{array}$ \\
\hline REGRESSOR & $\Delta \log S_{t-2}$ & & & & & \\
\hline$\underset{\operatorname{Pr}>F}{F}$ & $\begin{array}{c}0.84 \\
.5813\end{array}$ & & & & & \\
\hline
\end{tabular}

TABLE 4

CANONICAL CORRELATION ANALYSIS - COMMON CYCLES TEST

\begin{tabular}{||c|c|c|}
\hline $\begin{array}{c}\text { CANONICAL CORRELATIONS } \\
\left(\rho_{i}\right)\end{array}$ & Prob.>F & NULL HYPOTHESES \\
\hline 0.9836 & 0.0001 & Current and all smailer $\left(\rho_{i}\right)$ are zero \\
\hline 0.9460 & 0.0113 & Current and all smaller $\left(\rho_{i}\right)$ are zero \\
\hline 0.8640 & 0.4198 & Current and all smaller $\left(\rho_{i}\right)$ are zero \\
\hline 0.7652 & 0.7237 & Current and all smaller $\left(\rho_{i}\right)$ are zero \\
\hline 0.7163 & 0.7842 & Current and all smaller $\left(\rho_{i}\right)$ are zero \\
\hline 0.6609 & 0.8088 & Current and all smaller $\left(\rho_{i}\right)$ are zero \\
\hline 0.6226 & 0.7922 & Current and all smaller $\left(\rho_{i}\right)$ are zero \\
\hline 0.5268 & 0.7847 & Current and all smaller $\left(\rho_{i}\right)$ are zero \\
\hline
\end{tabular}


TABLE 5

SUMMARY STATISTICS OF SECTORAL OUTPUTS, CYCLES AND TRENDS

\begin{tabular}{rccccccccccc}
\hline & & $\begin{array}{c}\text { (log) LEVELS } \\
\left(y_{i t}\right)\end{array}$ & \multicolumn{4}{c}{$\begin{array}{c}\text { CYCLICAL } \\
\text { COMPONENT } \\
\left(y_{i t}^{c}\right)\end{array}$} & $\begin{array}{c}\text { TREND } \\
\text { COMPONENT } \\
\left(y_{i t}^{p}\right)\end{array}$ & $\begin{array}{c}\text { CORREL. } \\
\text { TREND AND } \\
\text { CYCLE }\end{array}$ \\
\hline SECTORS & $\hat{\mu}$ & $\hat{\sigma}$ & $\hat{\sigma} / \hat{\mu}$ & $\hat{\mu}$ & $\hat{\sigma}$ & $\hat{\sigma} / \hat{\mu}$ & $\hat{\mu}$ & $\hat{\sigma}$ & $\hat{\sigma} / \hat{\mu}$ & CORR $\left(y_{i i}^{p}, y_{i t}^{c}\right)$ \\
\hline A & 5.905 & 0.098 & 0.017 & 0.000 & 0.055 & - & 5.905 & 0.103 & 0.017 & $-0.3526^{b}$ \\
Con & 6.644 & 0.153 & 0.023 & 0.000 & 0.292 & - & 6.644 & 0.344 & 0.052 & $-0.8280^{a}$ \\
Min & 6.331 & 0.100 & 0.016 & 0.000 & 0.176 & - & 6.331 & 0.164 & 0.026 & $-0.8975^{a}$ \\
M & 7.782 & 0.250 & 0.032 & 0.000 & 0.120 & - & 7.782 & 0.256 & 0.033 & $-0.2801^{c}$ \\
T & 6.848 & 0.309 & 0.045 & 0.000 & 0.047 & - & 6.848 & 0.318 & 0.046 & $-0.2741^{c}$ \\
W & 7.441 & 0.289 & 0.039 & 0.000 & 0.040 & - & 7.441 & 0.288 & 0.039 & -0.0333 \\
F & 7.253 & 0.373 & 0.051 & 0.000 & 0.068 & - & 7.253 & 0.377 & 0.052 & -0.1489 \\
S & 7.230 & 0.355 & 0.049 & 0.000 & 0.079 & - & 7.230 & 0.367 & 0.051 & $-0.2661^{c}$ \\
\hline
\end{tabular}

Notes: (a) Significant at the $1 \%$ level. (b) Significant at the 5\% level. (c) Significant at the $10 \%$ level.

TABLE 6

VARIANCE DECOMPOSITION OF SECTORAL OUTPUT INNOVATIONS

\begin{tabular}{|c|c|c|c|c|}
\hline \multirow[b]{2}{*}{ SECTORS } & \multicolumn{3}{|c|}{$\begin{array}{l}\% \text { OF THE VARIANCE OF SECTORAL OUTPUT } \\
\text { INNOVATION ATTRIBUTED TO: }\end{array}$} & \multirow[b]{2}{*}{$S^{\prime} M^{\circ}$} \\
\hline & $\begin{array}{r}\text { TREND } \\
\text { INNOVATION } \\
\end{array}$ & $\begin{array}{r}\text { CYCLE } \\
\text { INNOVATION }\end{array}$ & $\begin{array}{r}\text { COVARIANCE } \\
\text { EFFECT }\end{array}$ & \\
\hline A & 146.7 & 40.2 & -86.9 & 100.1 \\
\hline Con & 208.3 & 262.7 & -369.1 & 101.8 \\
\hline Min & 177.5 & 256.1 & -333.6 & 100.0 \\
\hline $\mathrm{M}$ & 47.9 & 144.9 & -92.7 & 100.0 \\
\hline $\mathrm{T}$ & 245.2 & 90.4 & -227.0 & 108.6 \\
\hline W & 23.7 & 79.3 & 0.0 & 102.9 \\
\hline$F$ & 187.7 & 252.7 & -339.8 & 100.6 \\
\hline S & 246.3 & 177.0 & -319.8 & 103.4 \\
\hline
\end{tabular}

Notes: (a) Only computed when the correlation coefficients between trend and cycle innovations were significant at the $1 \%$ level. P-value for Wholesale/Retail Trade is 0.84 . (b) Sum may be different than 100 due to rounding errors. 
TABLE 7A VARIANCE DECOMPOSITION OF SECTORAL OUTPUT INNOVATIONS

\begin{tabular}{|c|c|c|c|}
\hline \multirow[b]{2}{*}{ SECTORS } & \multicolumn{2}{|c|}{$\begin{array}{l}\text { \% OF THE VARIANCE OF SECTORAL } \\
\text { OUTPUT INNOVATION } \\
\text { ATTRIBUTED TO: }\end{array}$} & \multirow[b]{2}{*}{ SUM } \\
\hline & $\begin{array}{r}\text { TREND } \\
\text { INNOVATION } \\
\end{array}$ & $\begin{array}{r}\text { CYCLE } \\
\text { INNOVATION } \\
\end{array}$ & \\
\hline $\begin{array}{c}\mathrm{A} \\
\text { Con } \\
\text { Min } \\
\mathrm{M} \\
\mathrm{T} \\
\mathrm{W} \\
\mathrm{F} \\
\mathrm{S} \\
\end{array}$ & $\begin{array}{r}72.6 \\
5.5 \\
5.7 \\
0.0 \\
68.4 \\
19.6 \\
5.8 \\
40.1 \\
\end{array}$ & $\begin{array}{r}27.4 \\
94.5 \\
94.3 \\
100.0 \\
31.6 \\
80.4 \\
94.2 \\
59.9 \\
\end{array}$ & $\begin{array}{l}100 \\
100 \\
100 \\
100 \\
100 \\
100 \\
100 \\
100\end{array}$ \\
\hline
\end{tabular}

TABLE 7B

VARIANCE DECOMPOSITION OF SECTORAL OUTPUT INNOVATIONS USES PRINCIPAL COMPONENTS

\begin{tabular}{rrrr}
\hline \hline & \multicolumn{2}{c}{$\begin{array}{c}\text { \% OF THE VARIANCE OF SECTORAL } \\
\text { OUTPUT INNOVATION } \\
\text { ATTRIBUTED TO: }\end{array}$} \\
\cline { 2 - 4 } SECTORS & TREND & CYCLE & SUM \\
& INNOVATION & INNOVATION & 100 \\
Con & 99.8 & 0.2 & 100 \\
Min & 86.5 & 13.5 & 100 \\
MT & 82.8 & 17.2 & 100 \\
W & 40.3 & 59.7 & 100 \\
F & 92.0 & 8.0 & 100 \\
S & 30.1 & 69.9 & 100 \\
\hline
\end{tabular}

Notes: (a) Denote $\eta_{i t}{ }^{\prime}=\left(\eta_{i p r}, \eta_{i c t}\right)^{\prime}$ as a stack of period $\boldsymbol{t}$ innovations in sector $\mathbf{i}$, where $\eta_{i p t}$ is the innovation in the trend and $\eta_{i c t}$ is the innovation in the cycle. Table $7 \mathrm{~A}$ presents the results of decomposing the variance of $I_{i t}=(1,1) \eta_{i t}$ - the total period $t$ innovation in sector $\mathrm{i}$, by using a lower triangular matrix $D_{i}$, such that $D_{i} \operatorname{VAR}\left(\eta_{i t}\right) D_{i}^{\prime}$ is diagonal for all $\mathrm{i}$, in the following way: $\operatorname{VAR}\left(I_{i t}\right)=\operatorname{VAR}\left[(1,1) D_{i}^{-1} D_{i} \eta_{i r}\right]$. The matrix $D_{i}$ used was:

$D_{i}=\left[\begin{array}{cc}1 & 0 \\ -\frac{\sigma_{i p c}}{\sigma_{i p p}} & 1\end{array}\right]$; where $\operatorname{VAR}\left(\eta_{i t}\right)=\left[\begin{array}{ll}\sigma_{i p p} & \sigma_{i p c} \\ \sigma_{i p c} & \sigma_{i c e}\end{array}\right]$.

(b) Table $7 \mathrm{~B}$ performs the same exercise with $\eta_{i t}{ }^{\prime}=\left(\eta_{i c t}, \eta_{i p t}\right)^{\prime}$ and:

$D_{i}=\left[\begin{array}{cc}1 & 0 \\ -\frac{\sigma_{i p c}}{\sigma_{i c c}} & 1\end{array}\right]$; where $\operatorname{VAR}\left(\eta_{i p}\right)=\left[\begin{array}{ll}\sigma_{i c c} & \sigma_{i p c} \\ \sigma_{i p c} & \sigma_{i p p}\end{array}\right]$. 
Figure 1

Sectoral Per-Capita GNP

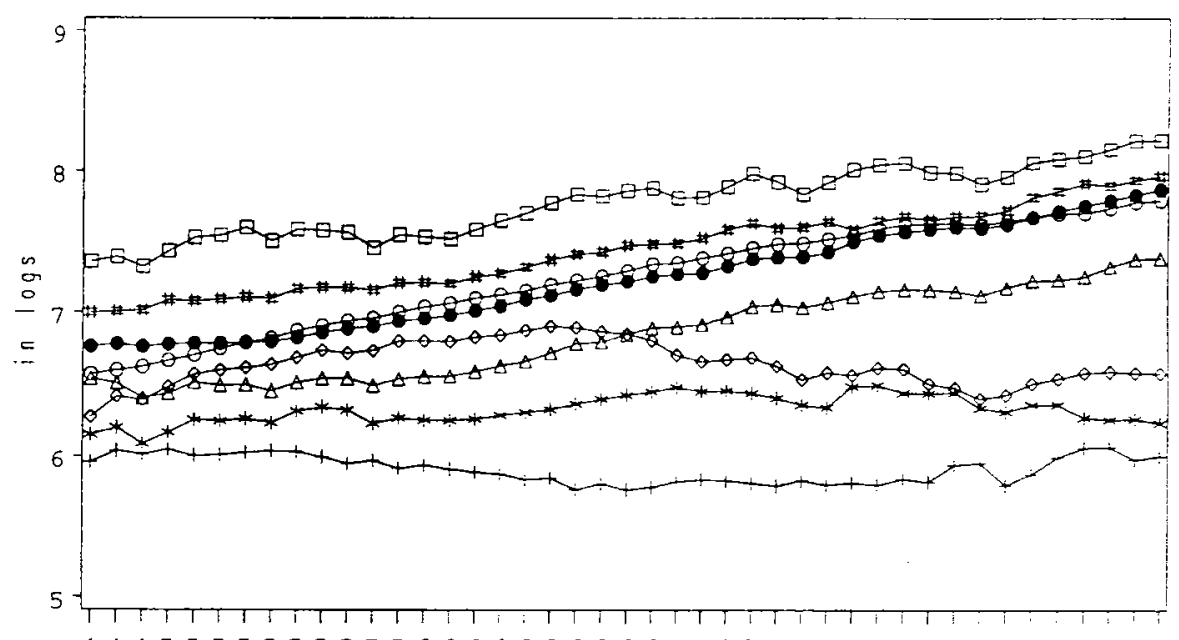

$44455555555556666666666777777777788888 \& 3888$ 7890123456789012345678901234567890123455789

YEAR

$\mathrm{A}=+\mathrm{Min}=$ * Con=diamond $\mathrm{M}=$ square $\mathrm{T}=$ triangle $\mathrm{W}=$ hash $F=c i r c l e s=00$ 
Figure 2

Sectoral Per-Capita GNP Shares

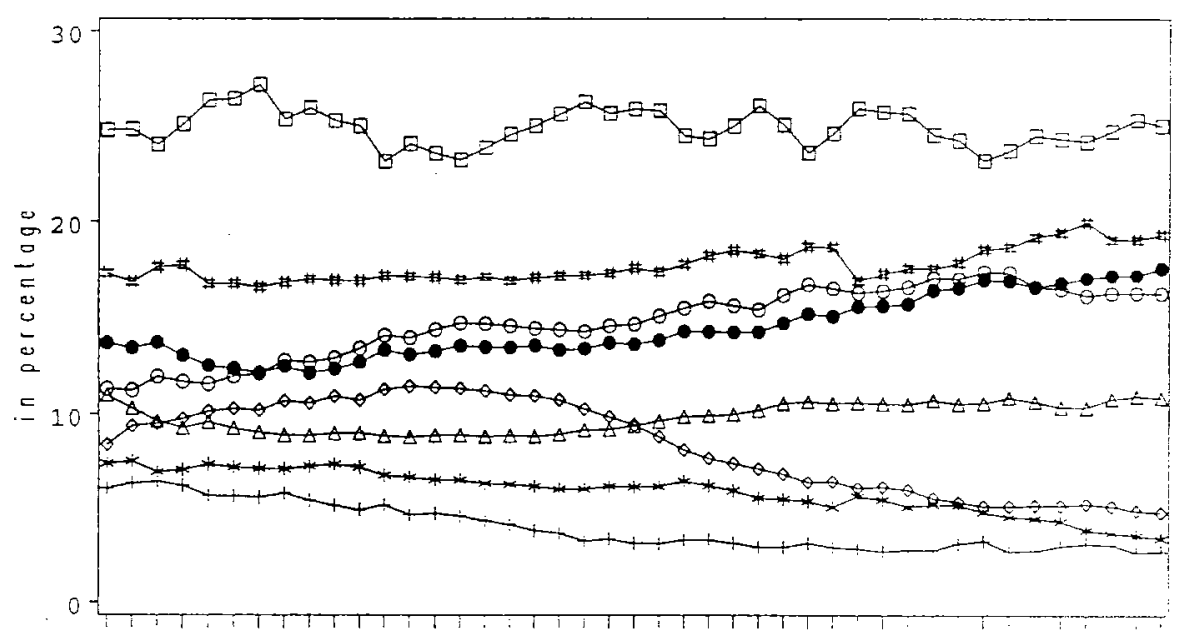

$44455555555556666666666777777777788 \varepsilon \varepsilon \varepsilon \varepsilon 3 \varepsilon 6 \varepsilon$

$78901234557890123456789012345678901234 \equiv 67 \varepsilon$

YEAR

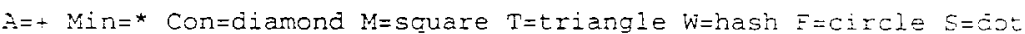


Figure 3

Detrended Error Correction Terms

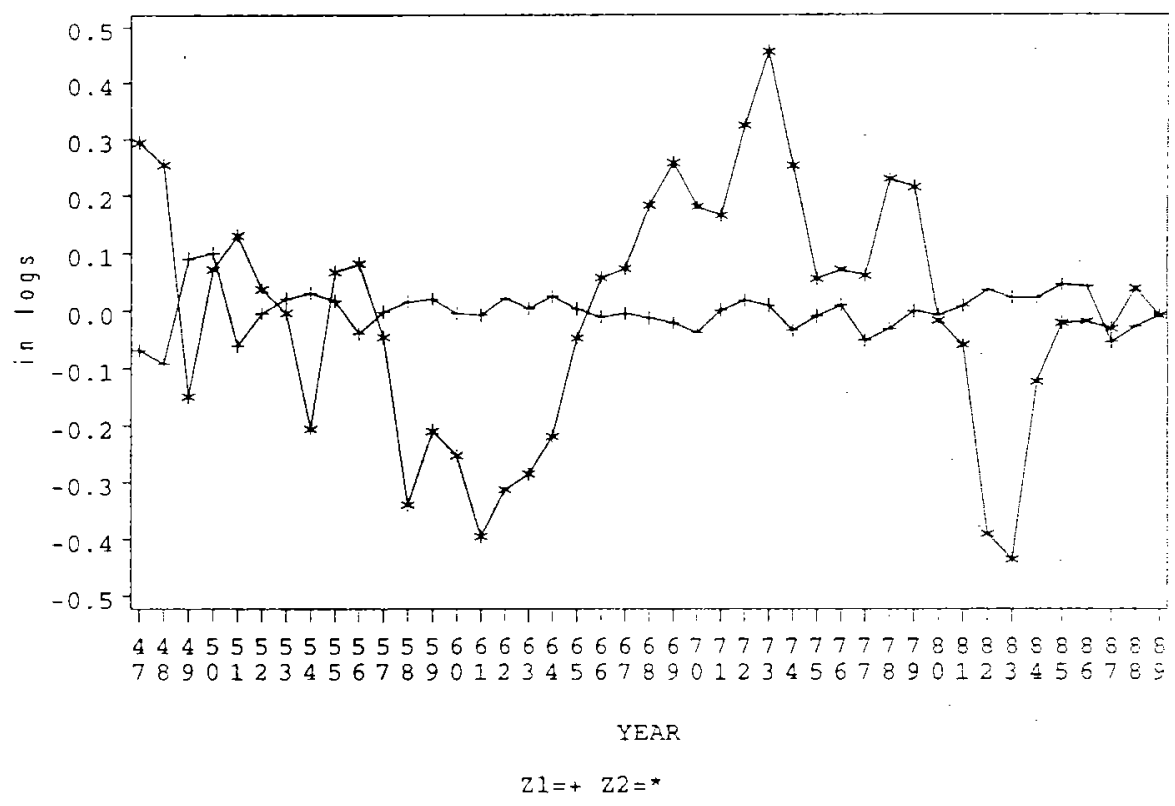


Figure 4

Per-Capita Agriculture GNP and its Trend

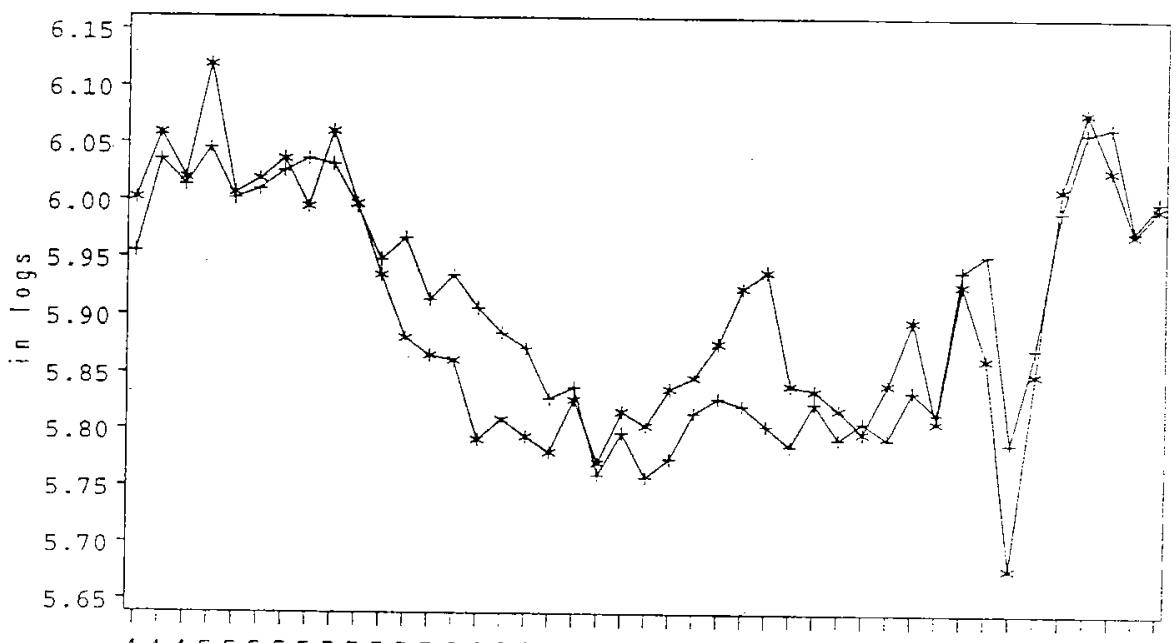

$44455555555556666656666777777777788888 \varepsilon \varepsilon \varepsilon \varepsilon \varepsilon$

7890123456789012345678901234567890123456789

YEAP

Sectcral GNP=+ Trend=* 
Figure 5

Per-Capita Mining GNP and its Trend

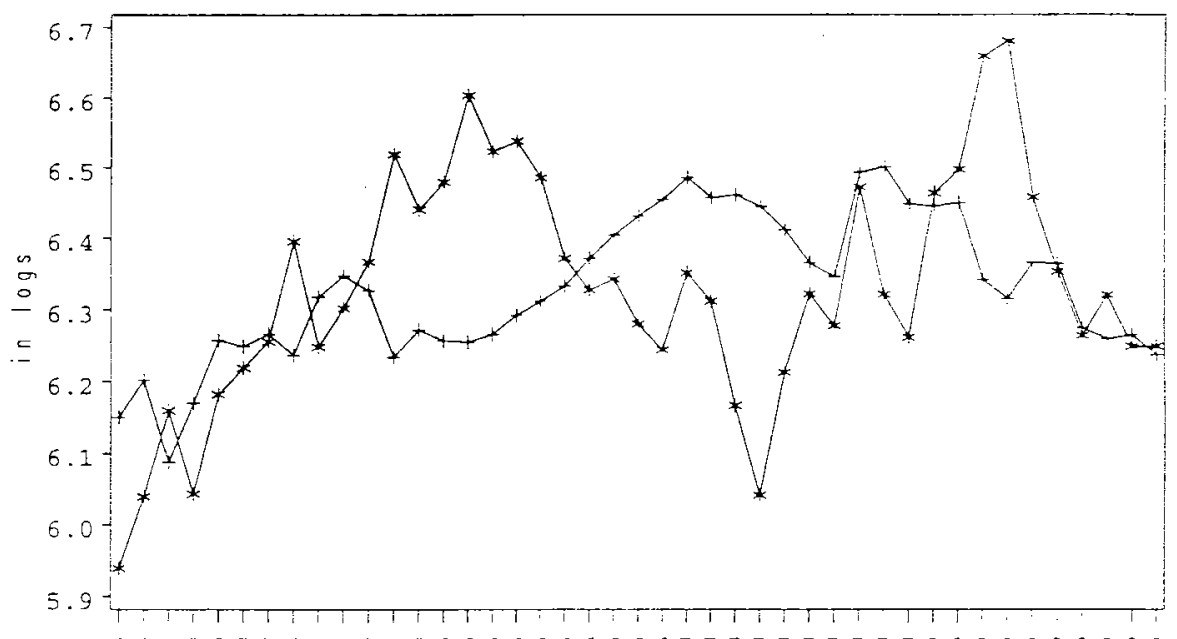

$44455555555556656566566777777777788888 \varepsilon 88 \varepsilon 8$

7890123456789012345678901234567890123455789

YERR

Sectoral GNP=+ Trend=* 
Figure 6

Per-Capita Construction GNP and its Trend

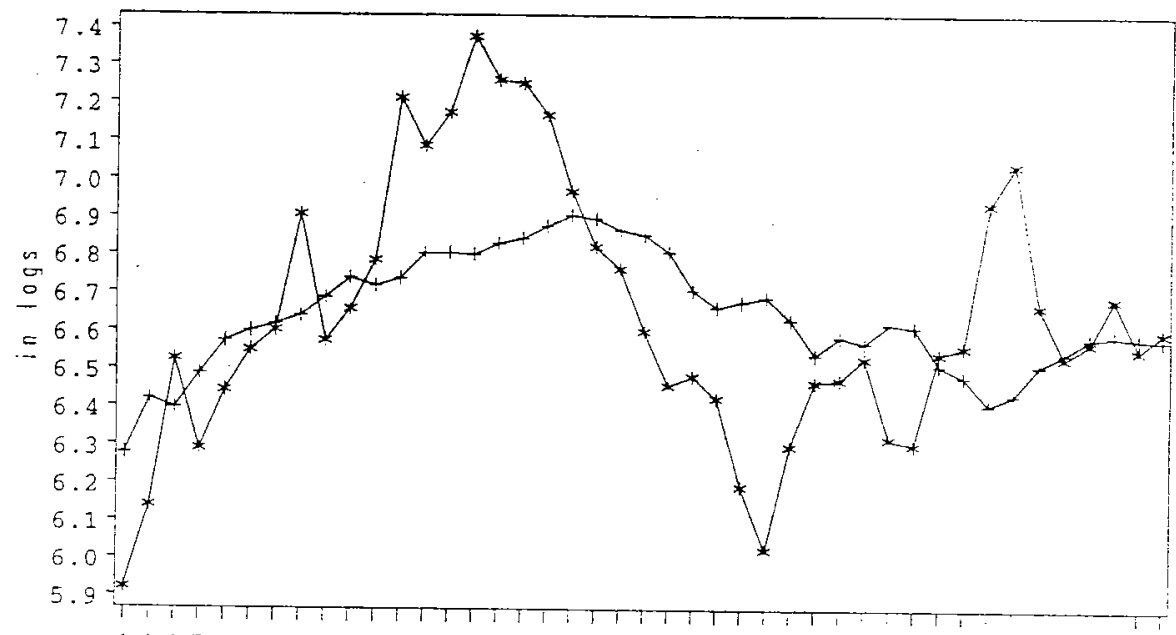

$44455555555556666666666777777777788888 \varepsilon 8 \varepsilon \varepsilon \varepsilon$ 7890123456789012345678901234567890123456789

YEAR

Sectora1 GNP=+ Trend=* 


\section{Figure 7}

Per-Capita Manufacturing GNP and its Trend

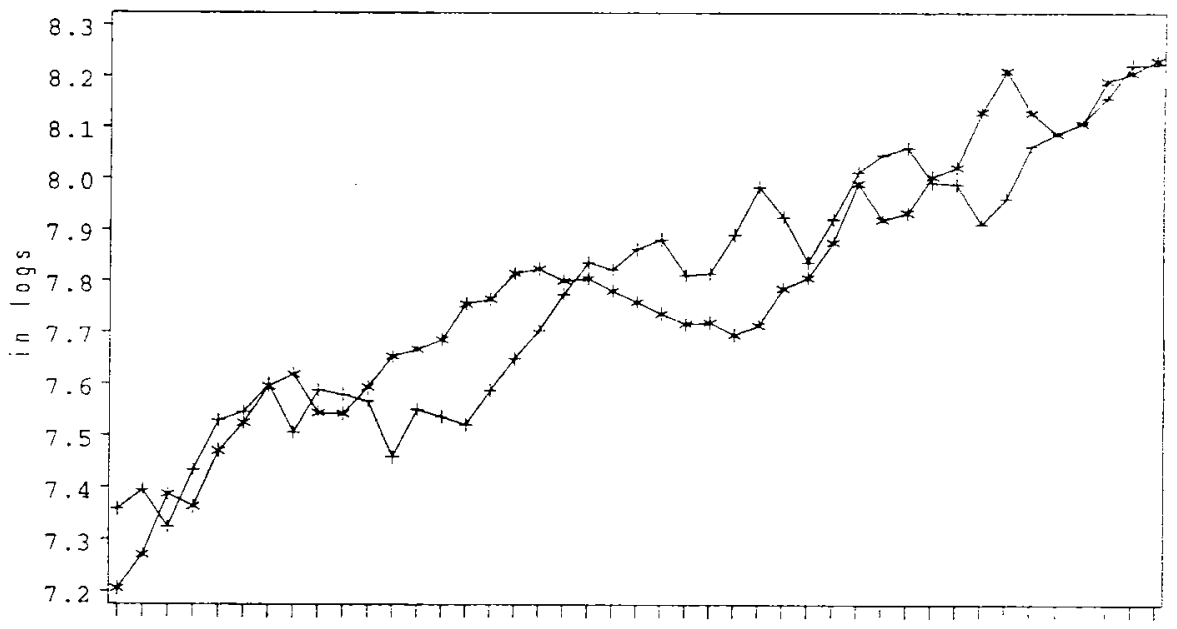

$44455555555556566666666777777777788888868 \varepsilon \approx$ 7890123456789012345678901234567890123456789

YEAR

Sectoral GNP=+ Trend=* 
Figure 8

Per-Capita Transportation GNP and its Trend

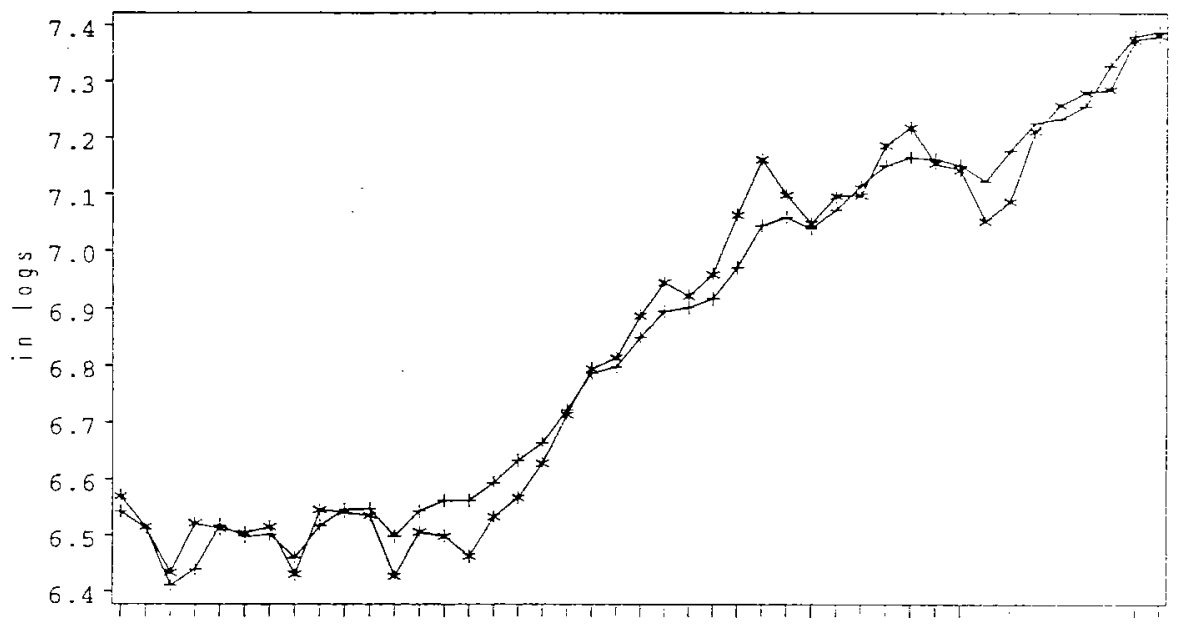

$444555555555566566665667777777777388 \varepsilon 8 \varepsilon 8 \varepsilon \varepsilon \varepsilon$ $78901234567890123456789012345678901234367 \varepsilon$

YEAR

Sectoral GNP $=+$ Trend=* 
Figure 9

Per-Capita Wholesale/Retail Trade GNP and its Trend

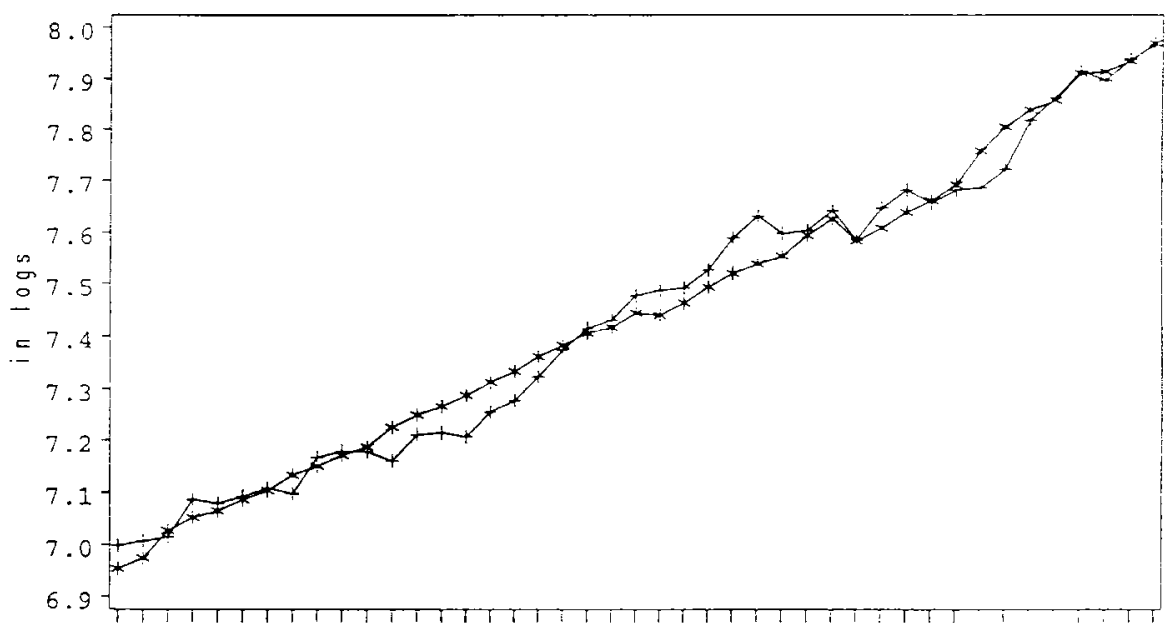

4445555555555666666665677777777778888588388 7890123456789012345678901234557890123456789

YEAR

Sectoral GNP=+ Trend=* 
Figure 10

Per-Capita Finance GNP and its Trend

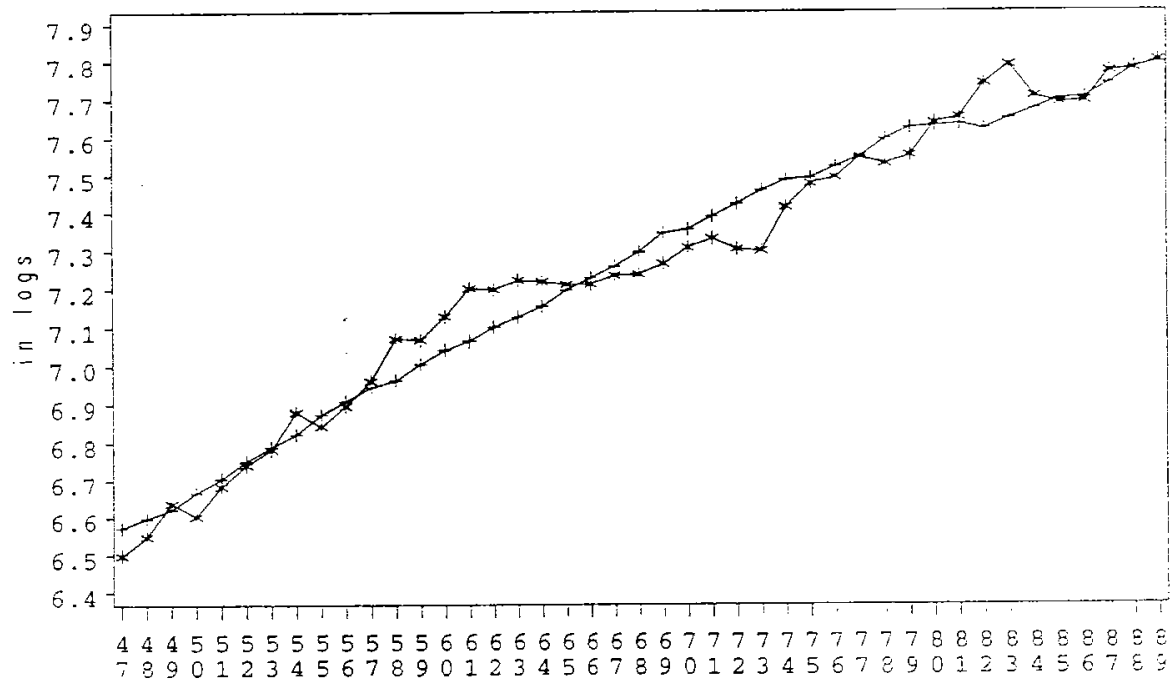

YEAR

Sectcral GNP $=+$ Trend $=$ * 
Figure 11

Per-Capita Services GNP and its Trend

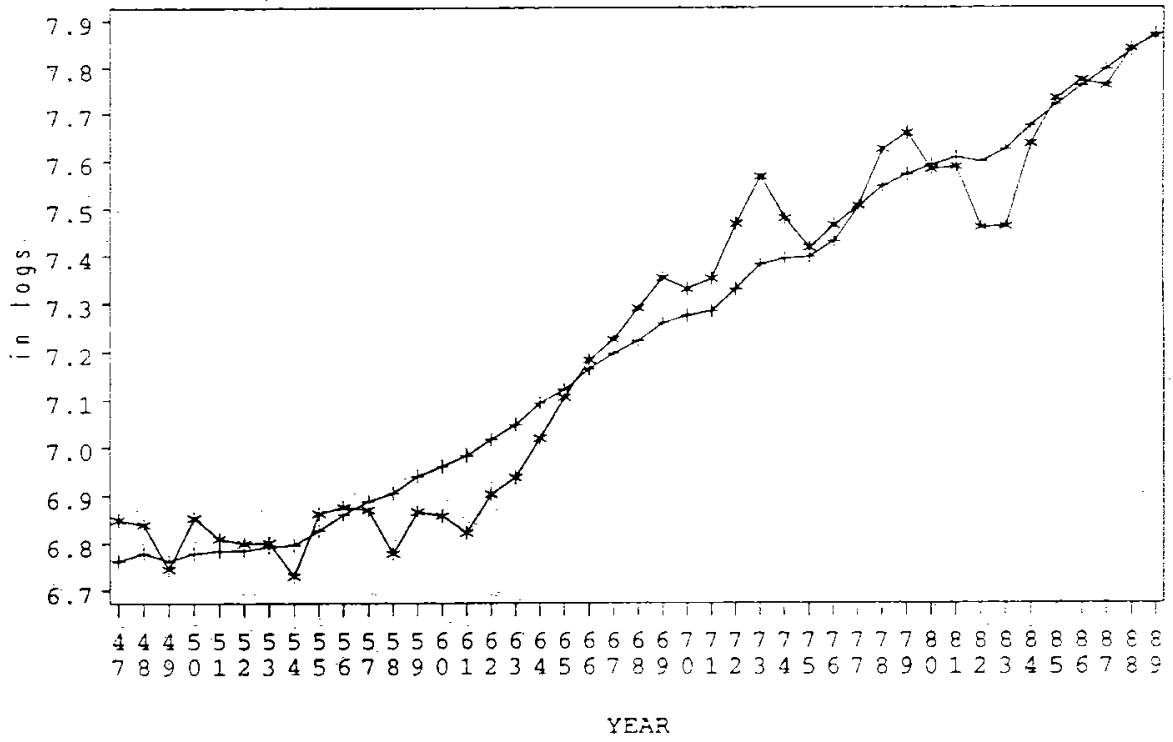

Sectoral GNP =+ Trend= * 
Figure 12

Detrended Error Correction Terms

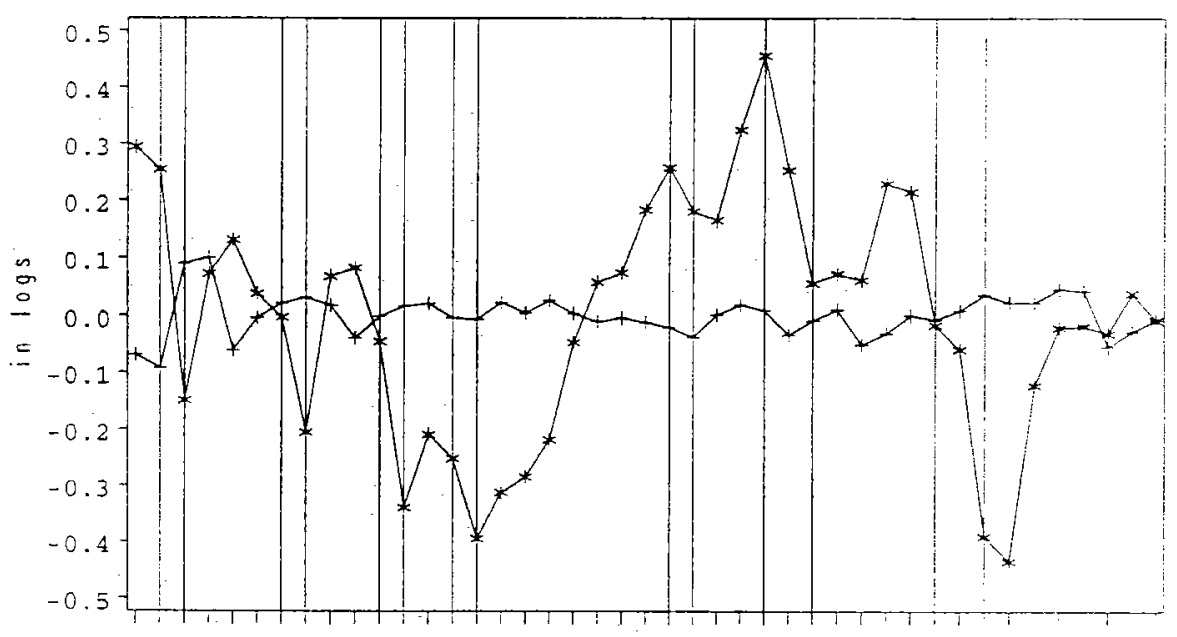

$4445555555555666666666677777777778888 \Xi \varepsilon \Xi 88 \varepsilon$

$78901234567890123456789012345678901224567 \varepsilon 5$

YEFR

$21=+22=*$ 
Figure 13

Cycles in Selected Sectors of Per-Capita GNP

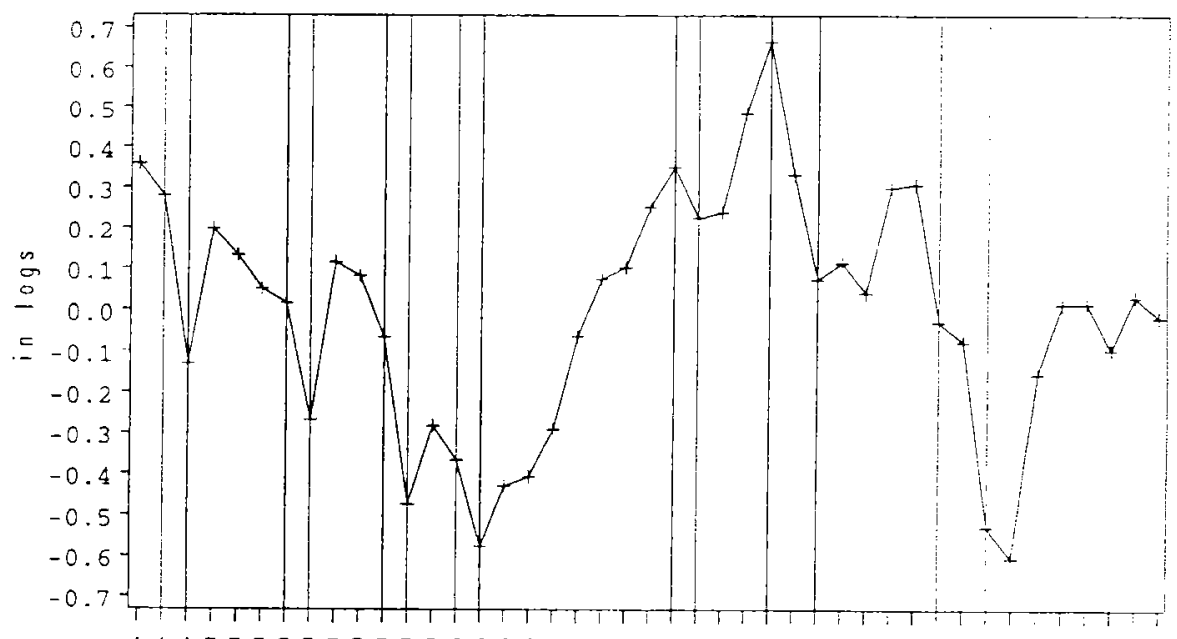

$4445555555555666666666677777777778888888 \varepsilon 3 \Xi$ $7890123456789012345678901234567890123 \leqslant 56789$

$Y E A P$

Construction=+ 
Figure 14

Cycles in Selected Sectors of Per-Capita GNP

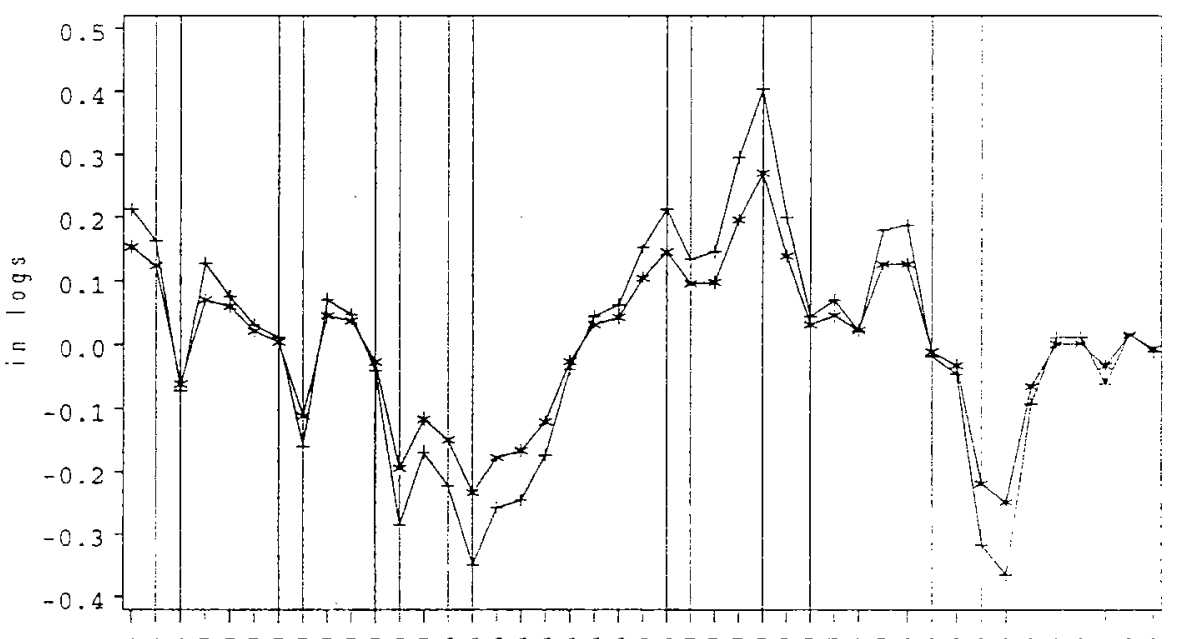

$4445555555555666666666677777777778888 \varepsilon \varepsilon \varepsilon 8 \varepsilon 8$

$7890123456789012345678901234567890122 \leqslant \equiv \equiv-\equiv \equiv$

YEAR

Mining=+ Manufacturing= * 
Figure 15

Cycles in Selected Sectors of Per-Capita GNP

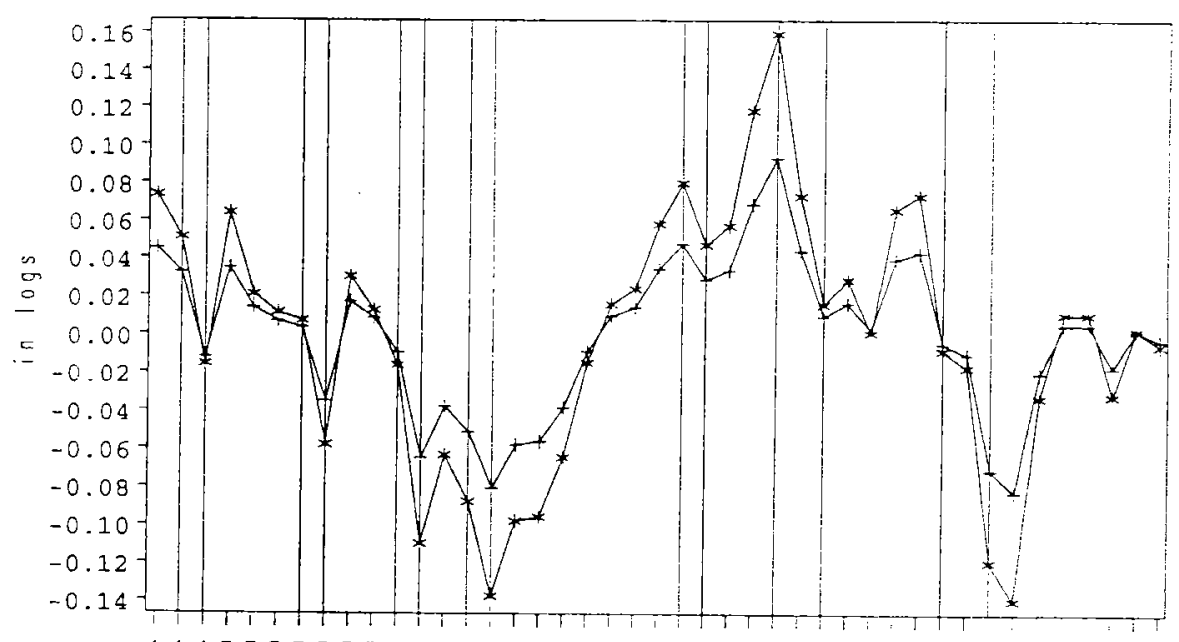

4445555555555666666666677777777778888888888 7890123456789012345678901234567890123455780

$Y E A R$

Wholesale/Retail Trade $=+$ Finance $=$ * 
Figure 16

Cycles in Selected Sectors of Per-Capita GNP

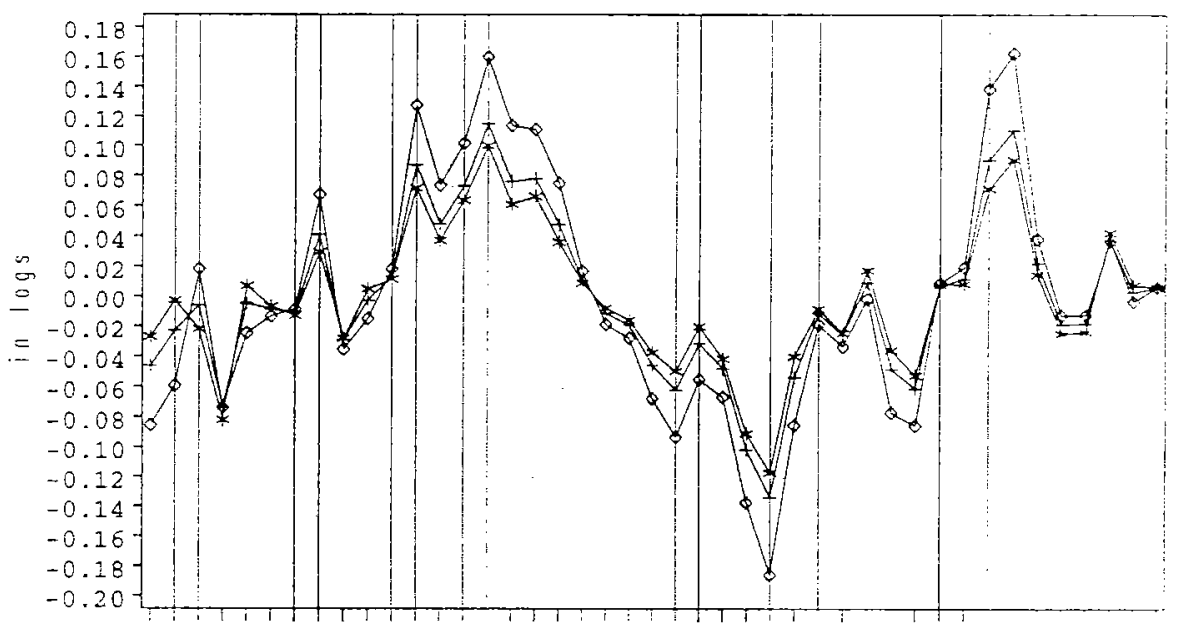

$4445555555555666666666577777777778 \varepsilon \varepsilon \varepsilon \varepsilon \varepsilon \varepsilon \Xi \Xi \varepsilon$

$78901234567890123456789012345673901235567 \varepsilon 5$

YEAR

Agiculture=+ Transportation=* Services=diamcnd 
Figure 17

Selected Sectoral Per-Capita Outputs

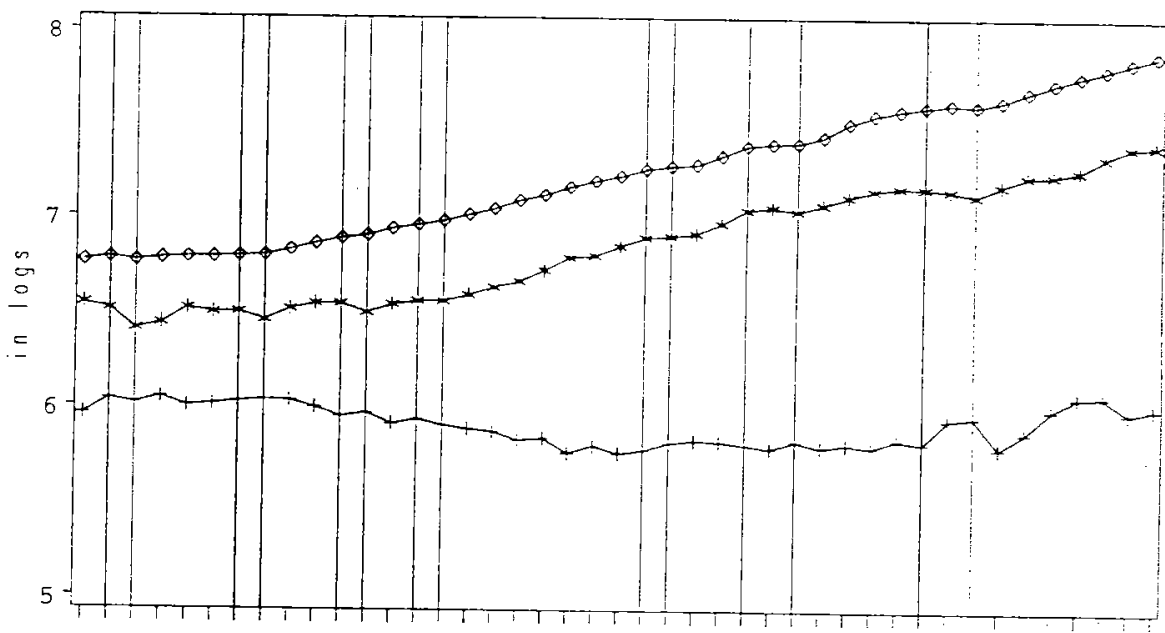

$4445555555555666666666677777777778 \varepsilon 888 \varepsilon 8 \varepsilon \varepsilon \varepsilon$ $78901234567890123456789012345678901234567 \hat{\varepsilon}$

YEAR

Agiculture=+ Transportation=* Services=diamond 